\title{
A Spatial Analysis of the Potato Cyst Nematode Globodera pallida in Idaho
}

\author{
J. B. Contina, L. M. Dandurand, ${ }^{\dagger}$ and G. R. Knudsen
}

First and second authors: University of Idaho, Department of Entomology, Plant Pathology and Nematology, 875 Perimeter Drive, MS 2329 , Moscow 83844-2329; and third author (G. R. Knudsen, deceased on 29 May 2016): University of Idaho, Department of Soil and Water Systems, 875 Perimeter Drive, MS 2340, Moscow 83844-2340.

Accepted for publication 5 March 2018.

\begin{abstract}
The potato cyst nematode Globodera pallida is a globally regulated and quarantine potato pest. It was detected for the first time in the United States in the state of Idaho in 2006. A spatial analysis was performed to (i) understand the spatial arrangement of fields infested with G. pallida in southern Idaho using spatial point pattern analysis, and (ii) evaluate the potential threat of $G$. pallida for entry to new areas using spatial interpolation techniques. Data point locations, cyst numbers and egg viability values for each infested field were collected by USDA-APHIS during 2006 to 2014. Results showed the presence of spatially clustered fields infested with G. pallida $(P=0.003)$. We determined that the spread of $G$. pallida grew in diameter from the original center of infestation toward the southwest as an ellipsoidal-shaped cluster. Based on the aggregated spatial pattern of distribution, we determined that G. pallida spread followed a contagion effect scenario, where nearby infested fields
\end{abstract}

ABSTRACT contributed to the infestation of new fields, probably through soil contaminated agricultural equipment or tubers. We determined that the presence of G. pallida in southern Idaho is unlikely to be associated with new introductions from outside the state of Idaho. The aggregation pattern of fields infested with $G$. pallida, with an average of 4,263 cysts/ha and egg viability of $25 \%$, facilitates quarantine activities and confines the propagation of this pest to a small area, which in 2017 was estimated to be 1,233 ha. The tools and methods provided in this study facilitate comprehensive approaches to improve G. pallida control and eradication programs as well as to raise public awareness of the problems surrounding this economically important potato pest.

Additional keywords: inverse distance weighting, nearest neighbor analysis, ordinary kriging, spatial aggregation.
The potato cyst nematode Globodera pallida (Behrens 1975; Stone 1972) is a globally regulated pest of potato (Solanum tuberosum) and is of great economic importance in many countries throughout the world (Hodda and Cook 2009; Turner and Rowe 2006). G. pallida and $G$. rostochiensis, both considered potato cyst nematodes, coevolved in South America with potato and other Solanum species at altitudes up to 2,000 $\mathrm{m}$ (Jones and Parrott 1968). Potatoes were introduced into Europe around 1570 (Evans et al. 1975); however, potato cyst nematodes arrived in Europe on tubers taken from the Andes around 1850 and the nematodes were first observed on potatoes in Germany in 1881, before spreading throughout the world (Baldwin and Mundo-Ocampo 1991; Jatala 1994; Jones 1970).

G. pallida is a highly specialized obligate endoparasitic nematode that requires a living potato plant as a host to complete its life cycle. G. pallida can survive in the soil for up to 30 years without a suitable host (Turner 1996). The cyst, which is the body of the dead female, contains 300 to 500 eggs. Cysts are usually spread by contaminated soils, tubers, or farm equipment (Evans and Stone 1977). Computer modeling showed that sufficient G. pallida eggs are likely to survive in the soil after nematicide applications, allowing a resurgence of large $G$. pallida populations in subsequent host crop cycle (Trudgill et al. 2003). When left uncontrolled, G. pallida can reduce tuber yields up to $80 \%$ (Talavera et al. 1998; Vasyutin and Yakovleva 1998). In Ukraine, where G. rostochiensis was first identified in 1963, Pylypenko (1999) reported that 55 eggs per gram of soil were associated with a yield loss of $3.3 \%$ in resistant potato, whereas susceptible cultivars suffered $37.7 \%$ yield loss in

†Corresponding author: L. M. Dandurand; E-mail address: 1md@uidaho.edu

Funding: This project was funded by the USDA National Institute of Food and Agriculture competitive grant number 2015-69004-23634.

(C) 2018 The American Phytopathological Society susceptible ones. Populations of 121 eggs per gram of soil were associated with losses of 16.9 and 63.3\%, respectively (Pylypenko 1999).

The first symptomatic presence of potato cyst nematodes in the UK was reported by a farmer in Yorkshire in 1904 (Massee 1913; Strachan and Taylor 1926). Since then, populations have become widespread in the major potato growing areas of the UK. In the presence of repeated cropping of susceptible potato cultivars, potato cyst nematode populations and the probability of their detection progressively increases. In 2000 , about $64 \%$ of potato fields in the UK were reported to be infested with potato cyst nematodes (Minnis et al. 2000, 2002).

In Europe, overall losses due to potato cyst nematodes are estimated to be about $9 \%$ of potato production (Turner and Rowe 2006). However, total losses of potato production can occur when no control or containment strategies are employed. Without action to prevent the spread and entry of potato cyst nematodes to new areas, Hodda and Cook (2009) estimated economic losses to Australian agriculture over a 20 -year period could exceed $\$ 370$ million.

G. pallida is a quarantine pest in the state of Idaho where it was found in 2006, during a routine inspection conducted jointly by the Idaho State Department of Agriculture (ISDA) and the U.S. Department of Agriculture's Animal and Plant Health Inspection Service (USDA-APHIS). Subsequent extensive sampling traced the nematode to two fields in northern Bingham County, Idaho (Hafez et al. 2007). The presence of G. pallida in Idaho constitutes a significant threat to the Idaho potato industry. Currently, Idaho is the nation's largest producer, packer, and processor of potatoes. Idaho has been the number one potato-producing state for the past 50 years, producing about $29 \%$ of the U.S. potato crop, $40 \%$ of U.S. processed potato products and one-third of the nation's fresh potato shipments (Anonymous 2014, 2017a).

G. pallida in Idaho is limited to a small area with low population levels and represents less than $1 \%$ of annual potato production areas, whereas in the UK more than $60 \%$ of potato fields are 
infested. Resistance to G. pallida in russet-type potato cultivars is currently unavailable for production in the U.S. Pacific Northwest. USDA-APHIS and ISDA have implemented a containment and eradication program designed to prevent $G$. pallida spread to other potato fields. The program outlines restrictions on the movement of plants and soil, requires sanitation procedures for equipment, and enforces limitations on planting potato in infested fields (Anonymous 2017b). The use of Solanum sisymbriifolium 'litchi tomato' as trap crop and chemical applications with the nematicide Telone II (1,3-dichloropropene) are being conducted in infested fields as part of the G. pallida eradication program. Current regulated areas in Idaho are limited to 3,777 ha, of which 1,233 ha are infested fields (Anonymous 2017b).

The invasion process of exotic nematode species consists of arrival, establishment, integration, and spread (Ferris et al. 2003). Plant-parasitic nematodes gain entry to new areas through imported agricultural commodities, while establishment and integration are achieved mainly through local nematode reproduction before spreading to nearby fields (Ferris et al. 2003). Intervention strategies to prevent the establishment of exotic nematodes include (Ferris et al. 2003) the following: (i) exclusion through cultural methods of control (use of certified seed) and quarantines (prohibition of planting host crops in infested fields); (ii) eradication of the nematode from infested sites (fumigation); and (iii) containment to minimize the potential spread of the nematode (restrictions of soil and plant materials movement, and decontamination of field equipment). However, when plantparasitic nematodes are long-established and integrated into the cropping system, a management program is required to keep the local population below the level of economic damage threshold or detection limit.

From an epidemiological perspective, spatial analysis of plant pathogen infestations in fields provides useful information on the spatial pattern and spatio-temporal dynamics of disease progression and outlines the probabilities of pathogens entering new areas. Therefore, spatial analysis and modeling techniques can be used to assess and evaluate the threat of plant diseases for agricultural production. The term 'spatial analysis' can be traced back to the 1950s, widely used in the Geographical Information Systems (GIS), and represents a collection of techniques and models that use the spatial referencing associated with each data value and attributes to explain a phenomenon (Haining 2003; Tobler 1979).

Spatial analysis is divided into three main components (Haining 2003): (i) cartographic modeling, where a data set is represented as a map; (ii) mathematical modeling, where the outcomes of a model are dependent on the characteristic of spatial interaction between the geographical positioning of objects within the model; and (iii) statistical application, where statistical tools and packages are used to fit spatial data into a predictive model.

Within spatial analysis, point pattern analysis is used to characterize the distribution pattern of a set of events delimited in the Euclidean space $R^{2}$ or $R^{3}$. Knowledge is generated by fitting models to patterns, while ascribing scientific interpretations to model parameters. Point pattern analysis is divided into two properties: (i) first-order property of point pattern analysis, where under the presence of complete spatial randomness (CSR), each random location of an event is drawn independently from an unknown distribution and is associated with a probability density function (Silverman 1986); and (ii) secondorder property of point pattern analysis, where the occurrences of events are related in some way (Ripley 1976, 1981).

CSR analysis validates that events are distributed randomly over a study region, and common tests performed under CSR hypothesis are quadrat analysis and maximum absolute deviation (Ripley 1977, 1981; Thomas 1977). The kernel density estimation (KDE) is used as a nonparametric method to estimate the probability density function of a random variable (Silverman 1986). The Ripley's Kfunction analysis is used as a second-order property of point pattern analysis to evaluate deviations of events from spatial homogeneity toward spatial clustering or dispersion (Ripley 1976, 1981) and is widely used in plant ecology; it has been applied to study the distribution patterns of herbs (Kenkel 1993), desert shrubs (Prentice and Werger 1985; Skarpe 1991), and tropical forest trees (Sterner et al. 1986).

Geostatistics is used as a tool of spatial interpolation analysis to process the effect of event aggregations or dispersions along with the uncertainties represented by spatial heterogeneity and to estimate a spatial prediction model known as kriging (Cressie 1993). Kriging is a linear unbiased spatial interpolation method that provides minimum mean-squared error estimates at unsampled locations and is controlled by semivariogram models, which quantify spatial variability of the data and provide information on the spatial autocorrelation of the datasets (Oliver 1990; Royle et al. 1981). Kriging generates spatial data using a number generator based on the specified semivariogram model and the pre-existing set of the sample data (Englund 1993). Other global interpolators like the nearest neighbor algorithm and the inverse distance weighting (IDW) are widely used in spatial interpolation analysis to approximate attributes to unsampled locations based on sampled ones within a study region. Unlike kriging, nearest neighbor and IDW are referred to as deterministic interpolation methods because they are directly based on the surrounding measured values or on specified mathematical formulas that determine the smoothness of the resulting surface (Jenkins et al. 1985).

Spatial analysis applied to plant-parasitic nematodes has been used to develop accurate sampling methods in fields (DinardoMiranda and Fracasso 2009; Francl 1986), determine ecological patterns of nematode distribution (Porazinska et al. 2012), support the use of site-specific management in nematode infested fields (Avendaño et al. 2003), model spatial pattern distribution of nematode populations, and estimate the likelihood of new infestation (Madden and Hughes 1995; Noe and Campbell 1985; Schomaker and Been 1999; Shaukat and Khan 1993). Schomaker and Been (1999) designed a model for infestation foci of potato cyst nematodes by using multiple sampling grids from 82 infested fields, and the data were analyzed and fitted for spatial distribution of cysts using exponential models. Gavassoni et al. (2001) used geostatistical analysis to quantify the effects of tillage on the spatial patterns of Heterodera glycines in infested fields. Evans et al. (2003) used spatial analysis to target "hot spots" of potato cyst nematode infestations for additional treatment with fumigant, thereby reducing the cost of chemicals applied and minimizing possible environmental damage.

Unlike the examples cited in the previous paragraph, our study focuses on using spatial analysis to define the spatial pattern of fields infested with G. pallida in southern Idaho at a regional level (macroscale) and it is not intended to describe G. pallida distribution at individual field (microscale). In this study, we proceeded in exploring the data by doing a cluster analysis followed by a point pattern analysis and spatial interpolation of fields infested with G. pallida using the attribute variables of number of cysts and the values of egg viability. There is a need to integrate spatial analysis into risk model assessment of plant diseases to widen the scope of control strategies and to identify potential hidden variables of interest. Such integration would allow remotely sensed biological data to be constantly monitored and to assess the success of control interventions in preventing or limiting the spread of exotic or native plant pathogens.

The objectives of this study were to describe the spatial distribution pattern of fields infested with G. pallida in southern Idaho and to evaluate the potential risk of $G$. pallida spread to new areas. G. pallida is known to be present in 1,233 ha in Idaho, which represent less than $1 \%$ of annual potato production areas. Therefore, a comprehensive spatial analysis will embolden policymakers and stakeholders to implement stringent phytosanitary measures to eradicate $G$. pallida from Idaho potato fields and will provide a framework of analysis for other exotic plant-parasitic nematodes. 


\section{MATERIALS AND METHODS}

Data collection. Data point locations of fields infested with G. pallida in southern Idaho with the associated number of cysts and the values of egg viability were collected by USDA-APHIS from 2006 to 2014 (Fig. 1; Table 1). Sampling system used by USDA-APHIS consisted in collecting $22.42 \mathrm{~kg}$ of soil samples per hectare. Soil samples were processed for cyst extractions using the Fenwick flotation method (Fenwick 1940). G. pallida egg viability was assessed using Meldola Blue as the staining agent (Ogiga and Estey 1974). The identity of G. pallida was confirmed by morphological and molecular methods (Skantar et al. 2007). The data collected are represented as a set of marked point pattern illustrated in algebraic terms as follows:

$$
y=\left\{\left(x_{i}, m_{i}\right), \ldots,\left(x_{n}, m_{n}\right)\right\}
$$

where $x_{i}$ are the locations of fields infested with $G$. pallida (longitude and latitude) and $m_{i}$ are the number of cysts collected or the values of egg viability. A conceptual framework was built to describe the spatial analysis processes used in this study (Fig. 2).

Data exploration. A distance matrix $(n \times n)$ was built using a pairwise distance measurement of fields infested with $G$. pallida. Agglomerative hierarchical cluster analysis was performed using
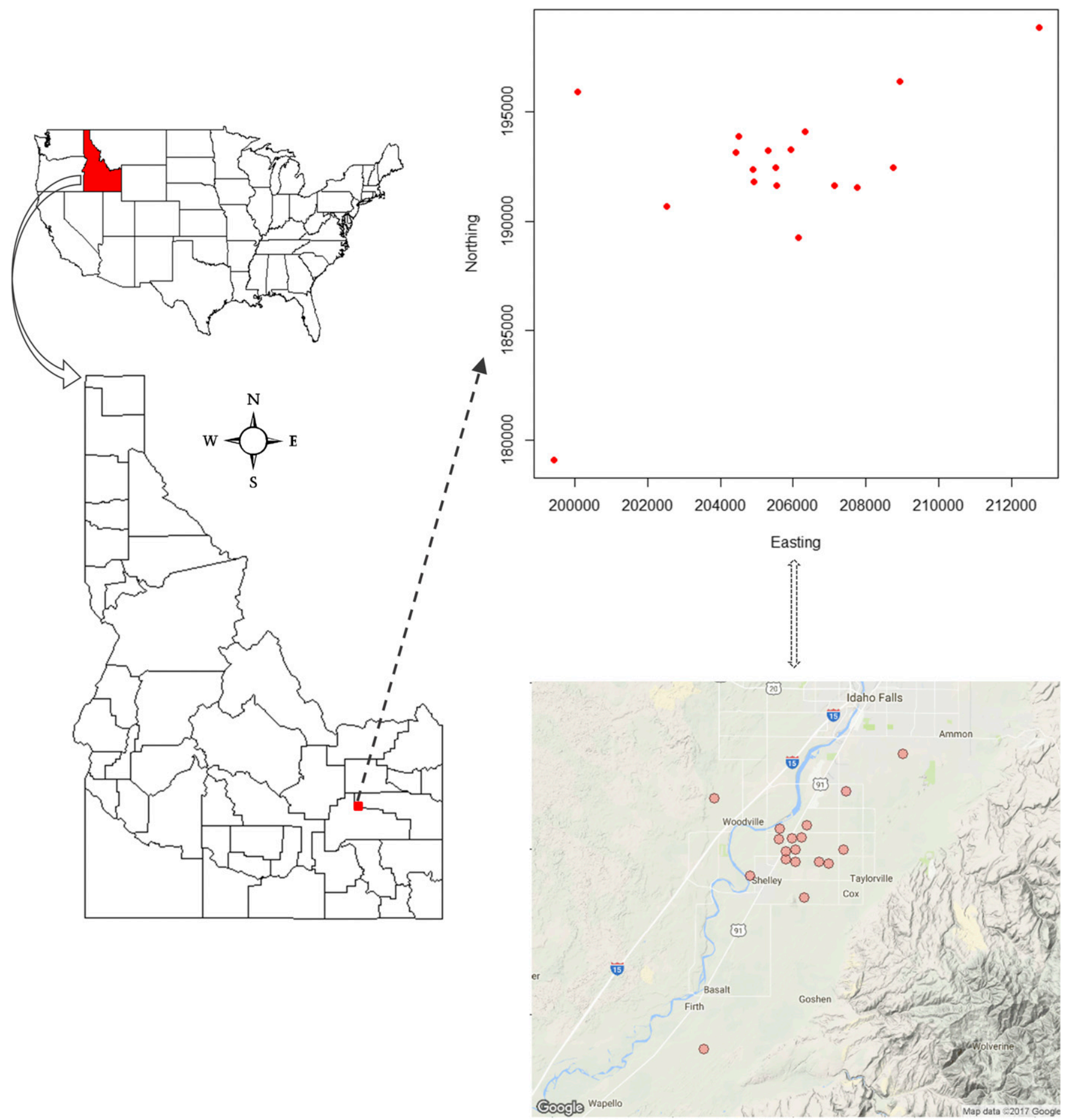

Fig. 1. Map of the state of Idaho (left) and location of the fields infested with Globodera pallida in southern Idaho (right). Globodera pallida was first found in 2006 in the Shelley, Idaho area located in Bingham County. The data used for spatial analysis in this study came from 18 infested potato fields where G. pallida cysts were collected, and egg viability was evaluated by USDA-APHIS. 
Ward's minimum variance method defined as the squared Euclidean distance between points (Ward 1963), as illustrated in algebraic terms:

$$
d_{i j}=d\left(\left\{X_{i}\right\},\left\{X_{j}\right\}\right)=X_{i}-X_{j}^{2}
$$

where $d_{i j}$ is the pairwise distances between clusters and $X_{i}, X_{j}$ are the distance points arranged in a matrix.

The variable number of cysts and variable egg viability were standardized before performing a cluster analysis using the average linkage method, where the distance between two clusters is defined as the average dissimilarities between the points in one cluster and the points in the other cluster (Kaufman and Rousseeuw 1990). The agglomerative coefficient, a quality index, was performed to measure the amount of clustering structure found (Rousseeuw 1986).

A nonparametric Mantel test, originally designed for analyzing disease clustering in epidemiological studies (Mantel 1967), was performed to evaluate the relationship between $G$. pallida-infested field distance matrix and the number of cysts and the values of egg viability. The variable cyst numbers were transformed into a logarithmic expression before running a Mantel test. The analysis was executed by running 1,000 replicates in a Monte-Carlo simulation. The Mantel test null hypothesis is the absence of relationship between values in two dissimilarity matrices and it is not intended to test the independence between two random variables or data tables (Legendre et al. 2015; Mantel and Valand 1970).

Point pattern analysis. The KDE was used as a first-order property of point pattern analysis under the assumption that each random location $x_{i}$ is drawn independently from an unknown distribution with probability density function $f\left(x_{i}\right)$. Silverman (1986) described KDE as the average of a series of small 'bumps' (probability distributions in two dimensions) centered on each observed point, as illustrated in algebraic terms:

$$
\hat{f}(x)=\hat{f}(x, y)=\frac{1}{n h_{x} h_{y}} \Sigma k\left(\frac{x-x_{i}}{h_{x}}, \frac{y-y_{i}}{h_{y}}\right)
$$

where $x, y$ is the coordinate point location, and $h_{x}, h_{y}$ are referred to as the bandwidths (which represent the radii of the bumps in each direction). A fixed bandwidth of 2,000 $\mathrm{m}$ was computed for $\mathrm{KDE}$ analysis used in this study.

The quadrat analysis, also known as the $\chi^{2}$ test of complete spatial randomness (Thomas 1977), was used to examine the frequency of points occurring in various parts of a study area. A set of quadrats of cells is superimposed on a study area, and number of points in each cell is determined. By analyzing the distribution of cell frequencies, the point pattern arrangement can be described using the variance and mean of point counts and the variance to mean ratio (VMR), as illustrated in algebraic terms,

$$
\mathrm{VAR}=\frac{\Sigma f_{i} x_{i}^{2}-\left[\frac{\left(\Sigma f_{i} x_{i}\right)^{2}}{m}\right]}{m-1}, \text { Mean }=\frac{n}{m}, \mathrm{VMR}=\frac{\mathrm{VAR}}{\text { Mean }}
$$

where VAR is the variance of the cell frequencies, Mean is the mean cell frequency, $f_{i}$ is the frequency of cells, $x_{i}$ is the number per cell, $n$ is the number of points, $m$ is the number of cells, and VMR is the variance to mean ratio. For a uniform (dispersed) intensity, the variance is equal to 0 and so is VMR. For a random intensity, the variance is equal to the mean and so VMR is equal to 1 . For a clustered intensity, the variance is greater than the mean and so VMR is greater than 1 .

In addition to being used as descriptive index, the VAR can be applied to test a distribution for randomness using $\chi^{2}$ statistical test, where the null hypothesis is the presence of complete spatial randomness.
The K-function was used as a second-order analysis of point pattern analysis (Ripley 1976, 1981). This process described situations in which the occurrences of events are related in some way. The K-function is a function of distance, defined by

$$
K(d)=\lambda^{-1} E\left(N_{d}\right)
$$

where $N_{d}$ is the number of events $x_{i}$ within a distance $d$ of a randomly chosen event from all recorded events $\left\{x_{1}, \ldots, x_{n}\right\}$, and $\lambda$ is the intensity of the process measured in events per unit area.

CSR or Poisson process occurred when the distributions of $x_{i}$ are independent and the marginal densities are uniform. Under CSR, the K-function is defined by

$$
K_{\mathrm{CSR}}(d)=\lambda \pi d^{2}
$$

where $d$ is the radius of a circle. When $K(d)>K_{\mathrm{CSR}}(d)$, excess of nearby points occurred, and the process is termed as a spatial clustering of points. When $K(d)<K_{\mathrm{CSR}}(d)$, this relation suggests the presence of spatial dispersion of points. The maximum absolute deviation (MAD) was used to evaluate the null hypothesis of CSR (Ripley 1977, 1981). MAD is consisted of the absolute value of the largest discrepancy between the two functions and was calculated using a Monte Carlo test based on 99 simulations:

$$
\mathrm{MAD}=\max _{d}\left|K(d)-K_{\mathrm{CSR}}(d)\right|
$$

Spatial interpolation. This method was used to estimate the values of the number of $G$. pallida cysts and egg viability at any point location within a study region. Spatial dependence allowed nearby locations to influence each other and to possess similar attributes. Given the value of the number of cysts or egg viability, such as $\left\{z_{1}, \ldots, z_{n}\right\}$ at locations $\left\{x_{1}, \ldots, x_{n}\right\}$, the objective is to estimate the value $z$ at some new point $x$. Three basic global interpolators were used to create estimated surfaces across the study region: (i) nearest neighbor algorithm, (ii) IDW, and (iii) ordinary kriging.

The nearest neighbor interpolation estimated the value $z$ at $x$ using the value $z_{i}$ at the closest observation point to $x$. Voronoi tessellation (Thiessen polygons) was used to divide the study region into zones, defined by boundaries located at equidistance between pairs of

TABLE 1. The list of fields infested with Globodera pallida in southern Idaho with the year of detection, the number of cysts per hectare, the values of egg viability, and the geographic point locations

\begin{tabular}{lcrrrr}
\hline Field & $\begin{array}{c}\text { Year of } \\
\text { G. pallida } \\
\text { detection }\end{array}$ & $\begin{array}{c}\text { Number of } \\
\text { G. pallida } \\
\text { cysts/ha }\end{array}$ & $\begin{array}{c}\text { Viability of } \\
\text { G. pallida } \\
\text { eggs }^{\mathrm{a}}\end{array}$ & Easting $^{\mathrm{b}}$ & Northing $^{\mathrm{b}}$ \\
\hline ID01 & 2006 & 7,416 & 0.13 & $204,912.6$ & $191,793.2$ \\
ID02 & 2006 & 10 & 0.39 & $205,322.2$ & $193,219.5$ \\
ID03 & 2006 & 10,934 & 0.18 & $205,538.4$ & $191,635.4$ \\
ID04 & 2006 & 4,374 & 0.33 & $207,136.9$ & $191,635.7$ \\
ID05 & 2006 & 996 & 0.25 & $205,936.9$ & $193,287.6$ \\
ID06 & 2006 & 1,611 & 0.36 & $206,337.6$ & $194,080.4$ \\
ID07 & 2006 & 44,523 & 0.20 & $204,433.5$ & $193,151.7$ \\
ID08 & 2007 & 961 & 0.09 & $205,527.8$ & $192,467.5$ \\
ID09 & 2008 & 141 & 0.31 & $204,497.3$ & $193,872.1$ \\
ID10 & 2011 & 5 & 0.25 & $208,926.5$ & $196,381.2$ \\
ID11 & 2011 & 210 & 0.45 & $212,759.2$ & $198,874.2$ \\
ID12 & 2012 & 5 & 0.15 & $204,908.0$ & $192,348.2$ \\
ID13 & 2012 & 5 & 0.21 & $207,769.3$ & $191,528.3$ \\
ID14 & 2012 & 7 & 0.05 & $200,081.2$ & $195,904.2$ \\
ID15 & 2012 & 111 & 0.00 & $202,527.8$ & $190,691.4$ \\
ID16 & 2013 & 89 & 0.50 & $206,141.0$ & $189,258.5$ \\
ID17 & 2013 & 5,234 & 0.30 & $208,758.5$ & $192,456.3$ \\
ID18 & 2014 & 104 & 0.28 & $199,417.4$ & $179,078.1$ \\
\hline
\end{tabular}

a The values of $G$. pallida egg viability represent the proportions of eggs that are viable from extracted cysts (i.e., a value of 0.13 means that $13 \%$ of eggs contained inside a cyst are viable and likely to be hatched).

b Easting (the $x$-coordinate) and northing (the $y$-coordinate) are geographic Cartesian coordinates for a point and are measured in meters. 
points, where the number of cysts or the value of egg viability for each corresponding set of points were estimated.

The IDW used similar techniques as the nearest neighbor approach; however, a weighted mean of nearby observations is taken, rather than relying on a single nearest neighbor. The IDW can be expressed algebraically as follows:

$$
\hat{z}(x)=\frac{\sum_{i} w_{i} z_{i}}{\sum_{i} w_{i}}, w_{i}=\left|x-x_{i}\right|^{-\alpha}
$$

where $\alpha \geq 0$, as an inverse square relationship.

The ordinary kriging was used as a probabilistic interpolator to estimate the value of a random variable, $z$, at one or

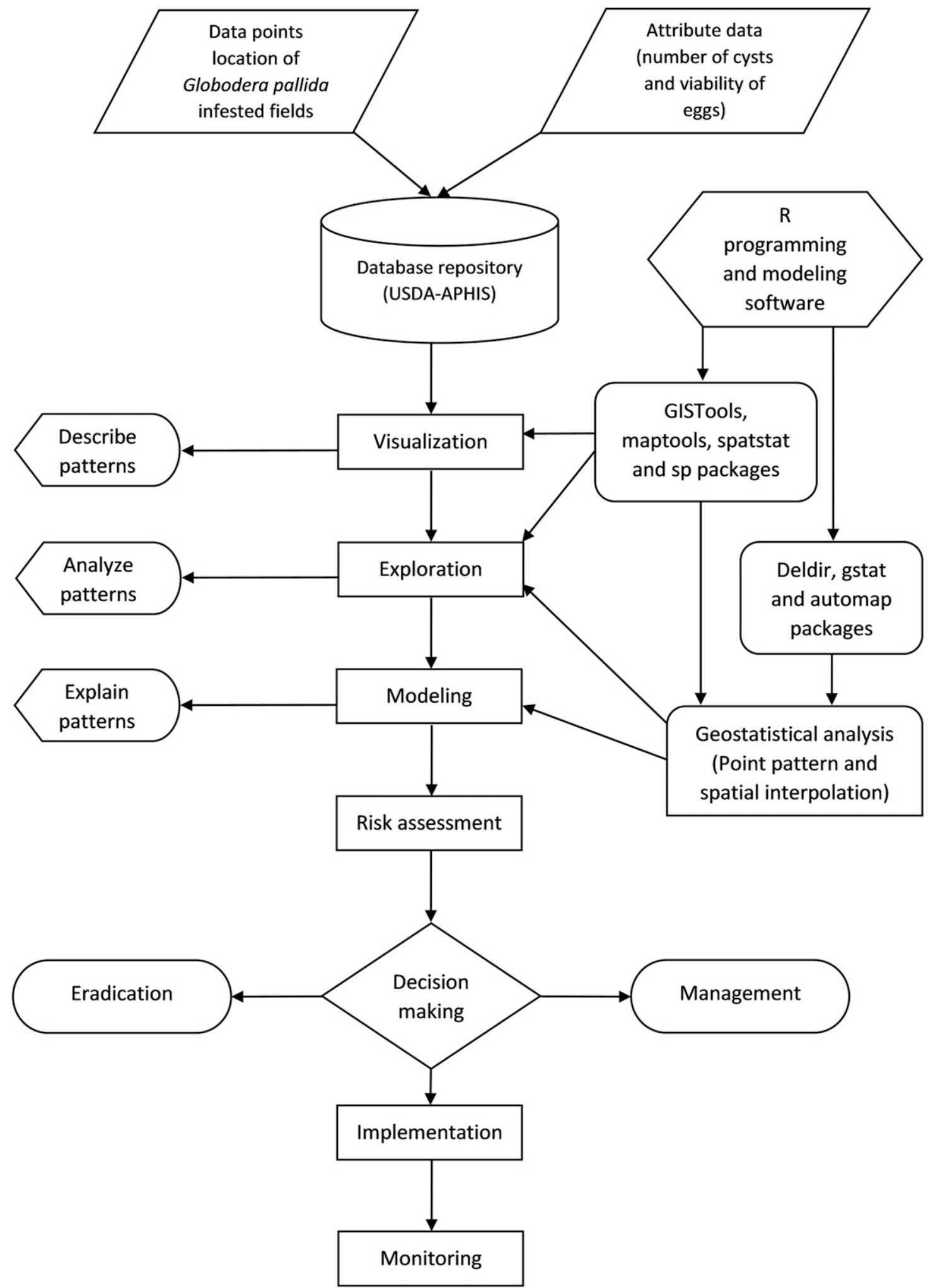

Fig. 2. Conceptual framework for spatial analysis of Globodera pallida in southern Idaho. The diagram provides a succinct summary of the methodology applied in this study. It consists of data retrieval, data analysis, and processing using R programming software and elaboration of a decision-making statement based on the results. Spatial analytical methods used included the following: (i) nearest neighbor algorithm and inverse distance weighting, as deterministic interpolators; and (ii) ordinary kriging method as probabilistic interpolator. 
more unsampled points. The kriging estimate of variable $z$ at point $x_{0}, \hat{z}\left(x_{0}\right)$, is a linear weighted sum of $n$ observations surrounding the estimate (Armstrong and Boufassa 1988; Stein 1999):

$$
\hat{z}\left(x_{0}\right)=\sum_{i=1}^{n} \lambda_{i} z\left(x_{i}\right)
$$

where $\lambda_{i}$ are the weights and $z\left(x_{i}\right)$ is the known value of variable $z$ at sampling site $x_{i}$.

An ordinary kriging was performed to interpolate the values of egg viability. For the interpolation of the number of cysts, due to the strong positive skewness of the cyst values, the data were transformed into a logarithmic expression. Consequently, an ordinary lognormal kriging was performed to interpolate the number of cysts from sampled areas to unsampled ones.

Kriging, as a probabilistic interpolator, relies on an experimental variogram to measure the spatial correlation of the random function $\hat{z}\left(x_{0}\right)$ (Stein 1999; Wackernagel 2003). The variogram is defined by calculating the semivariance as a function of distance:

$$
\gamma(d)=\frac{1}{2} \Sigma\left\{\left[\hat{z}\left(x_{1}\right)-\hat{z}\left(x_{2}\right)\right]^{2}\right\}
$$

Data analysis. $\mathrm{R}$ version 3.4.1 was used as a modeling language environment for data exploration and spatial analysis in this study (R Core Team 2017). For data exploration, the following packages were used: (i) 'cluster' and 'heatmap3' were used to perform the agglomerative hierarchical cluster analysis; and (ii) 'ade4' and 'ecodist' were used to calculate the Mantel correlation test for dissimilarity matrices. For spatial point pattern analysis, the following packages were used: (i) 'GISTools', 'maptools', and 'sp' were used to map the study area and to calculate the kernel

\begin{tabular}{|c|c|c|c|c|c|c|c|c|c|c|c|c|c|c|c|c|c|c|}
\hline Field & ID01 & ID02 & ID03 & ID04 & ID05 & ID06 & ID07 & ID08 & ID09 & ID10 & ID11 & ID12 & ID13 & ID14 & ID15 & ID16 & ID17 & ID18 \\
\hline ID01 & 0 & 1 & 1 & 2 & 2 & 3 & 1 & 1 & 2 & 6 & 11 & 1 & 3 & 6 & 3 & 3 & 4 & 14 \\
\hline ID02 & 1 & 0 & 2 & 2 & 1 & 1 & 1 & 1 & 1 & 5 & 9 & 1 & 3 & 6 & 4 & 4 & 4 & 15 \\
\hline ID03 & 1 & 2 & 0 & 2 & 2 & 3 & 2 & 1 & 2 & 6 & 10 & 1 & 2 & 7 & 3 & 2 & 3 & 14 \\
\hline ID04 & 2 & 2 & 2 & 0 & 2 & 3 & 3 & 2 & 3 & 5 & 9 & 2 & 1 & 8 & 5 & 3 & 2 & 15 \\
\hline ID05 & 2 & 1 & 2 & 2 & 0 & 1 & 2 & 1 & 2 & 4 & 9 & 1 & 3 & 6 & 4 & 4 & 3 & 16 \\
\hline ID06 & 3 & 1 & 3 & 3 & 1 & 0 & 2 & 2 & 2 & 3 & 8 & 2 & 3 & 7 & 5 & 5 & 3 & 17 \\
\hline ID07 & 1 & 1 & 2 & 3 & 2 & 2 & 0 & 1 & 1 & 6 & 10 & 1 & 4 & 5 & 3 & 4 & 4 & 15 \\
\hline ID08 & 1 & 1 & 1 & 2 & 1 & 2 & 1 & 0 & 2 & 5 & 10 & 1 & 2 & 6 & 3 & 3 & 3 & 15 \\
\hline ID09 & 2 & 1 & 2 & 3 & 2 & 2 & 1 & 2 & 0 & 5 & 10 & 2 & 4 & 5 & 4 & 5 & 4 & 16 \\
\hline ID10 & 6 & 5 & 6 & 5 & 4 & 3 & 6 & 5 & 5 & 0 & 5 & 6 & 5 & 9 & 9 & 8 & 4 & 20 \\
\hline ID11 & 11 & 9 & 10 & 9 & 9 & 8 & 10 & 10 & 10 & 5 & 0 & 10 & 9 & 13 & 13 & 12 & 8 & 24 \\
\hline ID12 & 1 & 1 & 1 & 2 & 1 & 2 & 1 & 1 & 2 & 6 & 10 & 0 & 3 & 6 & 3 & 3 & 4 & 14 \\
\hline ID13 & 3 & 3 & 2 & 1 & 3 & 3 & 4 & 2 & 4 & 5 & 9 & 3 & 0 & 9 & 5 & 3 & 1 & 15 \\
\hline ID14 & 6 & 6 & 7 & 8 & 6 & 7 & 5 & 6 & 5 & 9 & 13 & 6 & 9 & 0 & 6 & 9 & 9 & 17 \\
\hline ID15 & 3 & 4 & 3 & 5 & 4 & 5 & 3 & 3 & 4 & 9 & 13 & 3 & 5 & 6 & 0 & 4 & 6 & 12 \\
\hline ID16 & 3 & 4 & 2 & 3 & 4 & 5 & 4 & 3 & 5 & 8 & 12 & 3 & 3 & 9 & 4 & 0 & 4 & 12 \\
\hline ID17 & 4 & 4 & 3 & 2 & 3 & 3 & 4 & 3 & 4 & 4 & 8 & 4 & 1 & 9 & 6 & 4 & 0 & 16 \\
\hline ID18 & 14 & 15 & 14 & 15 & 16 & 17 & 15 & 15 & 16 & 20 & 24 & 14 & 15 & 17 & 12 & 12 & 16 & 0 \\
\hline
\end{tabular}

TABLE 2. A distance matrix of the fields infested with Globodera pallida in southern Idaho ${ }^{\mathrm{a}}$

a The distances between fields are measured in pairwise comparisons and are expressed in kilometers.

A

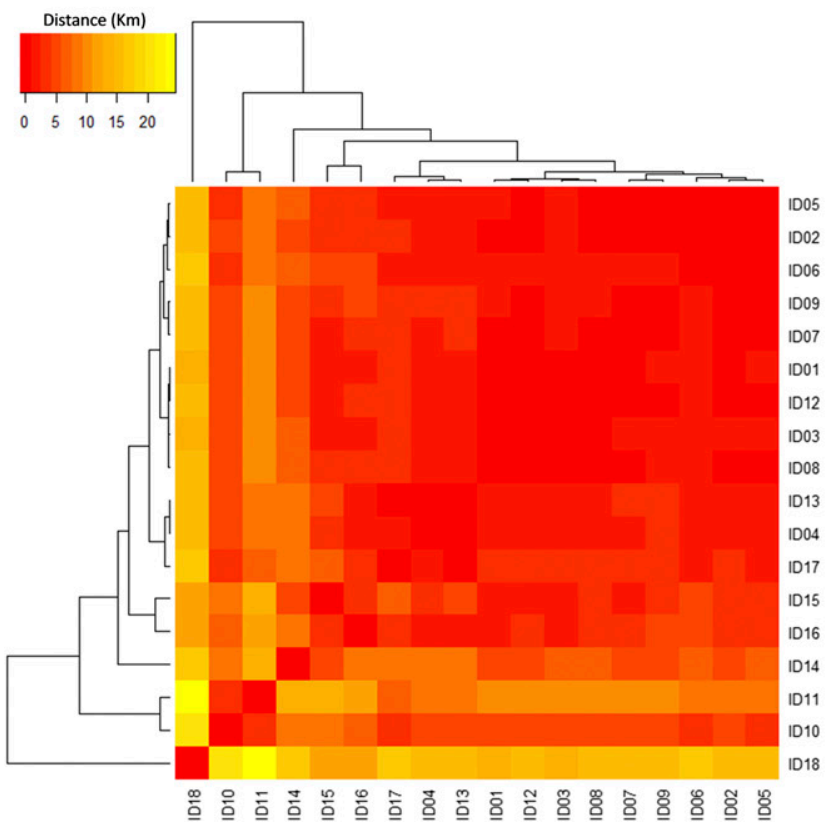

B

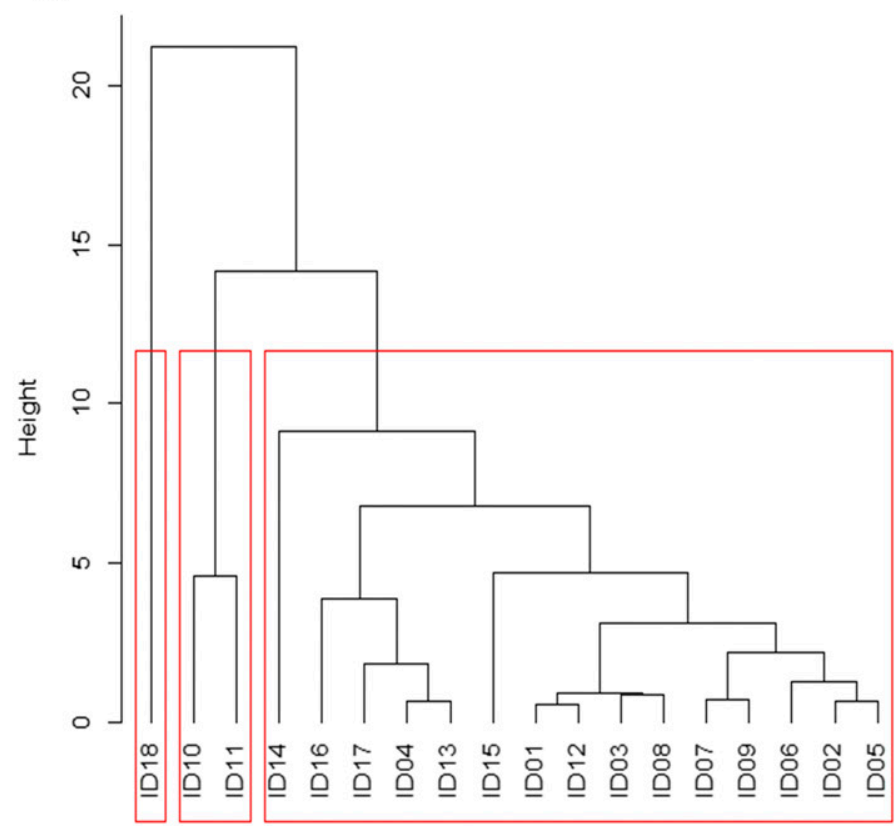

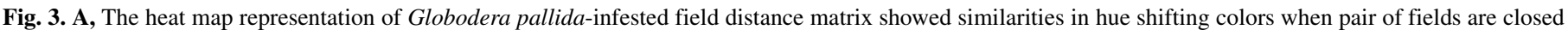

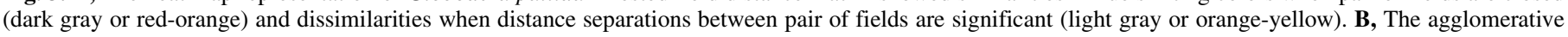

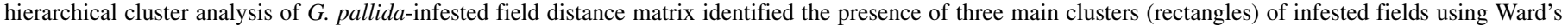
minimum variance method defined as the squared Euclidean distance between points. 
density estimation; and (ii) 'spatstat' was used to estimate the Ripley's K-function, the quadrat analysis for the $\chi^{2}$ test and the maximum absolute deviation test. For spatial interpolation, the following packages were used: (i) 'deldir' was used to calculate the Voronoi tessellation for the nearest neighbor estimation; (ii) 'gstat' was used to calculate the IDW; and (iii) 'automap' package was used to estimate the ordinary kriging and the ordinary lognormal kriging. The 'automap' package automatically fits a variogram to the data and provides initial estimates for the sill (variance), range (distance at which the variogram reaches the sill), nugget (error measurement), and kappa (a smoothing parameter). A kriging prediction and a standard error maps were also generated in this procedure.

\section{RESULTS}

The distance matrix, based on the distances between fields infested with $G$. pallida in pairwise comparisons, revealed that most of the infested fields are separated from each other at distances ranging from 1 to 5 kilometers (Table 2). However, three infested fields (ID10, ID11, and ID18) had greater distance separation from neighboring fields, ranging from 5 to $24 \mathrm{~km}$ (Table 2). Additionally, the heat map highlighted hue shifting colors for these three fields from nearby ones (Fig. 3A). The agglomerative hierarchical cluster analysis applied on the distance matrix identified three main clusters of fields infested with G. pallida using Ward's minimum variance algorithm (Fig. 3B). Similarly, standardized data values of cyst number and egg viability identified, based on their combined weight, three main clusters of fields infested with G. pallida using the average linkage method (Fig. 4). The agglomerative coefficient was 0.87 , representing a high-quality index for the amount of clustering structure found.

The Mantel correlation test showed no significant relationship between the field distance matrix and the number of cysts collected $\left(P=0.93\right.$ and $\left.R^{2}=-0.15\right)$ (Table 3$)$. Similarly, the Mantel correlation test between the field distance matrix and the values of egg viability showed no significant relationship $(P=0.28$ and $\left.R^{2}=0.08\right)$ (Table 3).

The KDE showed the densities of G. pallida-infested fields point locations in the study area. The KDE visual illustration of the color density map revealed areas with strong yellow (light gray) and red

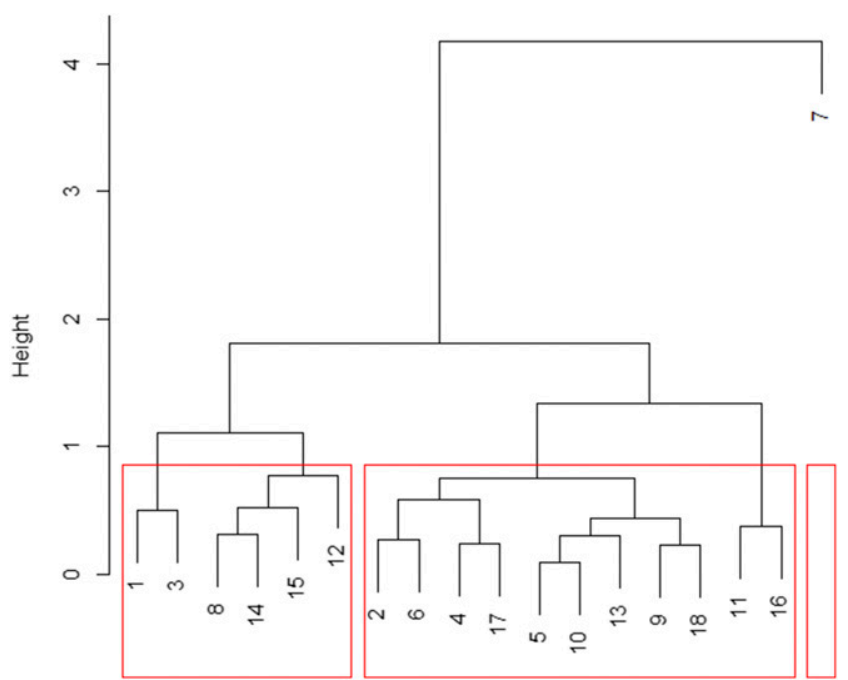

Fig. 4. The agglomerative hierarchical cluster analysis applied on the standardized data values of Globodera pallida cyst number and egg viability identified, based on their combined weight, three main clusters (rectangles) of fields infested with $G$. pallida using the average linkage method. The agglomerative coefficient was 0.87 , representing a high-quality index for the amount of clustering structure found. colors (dark gray) corresponding to point locations of high density of fields infested with G. pallida (Fig. 5A). A 3-D representation of KDE displayed a smooth peak of high density incidence with a fixed bandwidth of 2,000 m (Fig. 5B).

The $\chi^{2}$ test of CSR using quadrat counts revealed significant spatial clustering of fields infested with G. pallida $(P=0.003)$. This result showed that the infested fields, rather than being distributed randomly across the study area, followed a pattern of distribution toward aggregation as confirmed by the low $P$ value from the $\chi^{2}$ test.

The Ripley's K-function analysis illustrated evidence of spatial clustering as the observed K-function values, generated by 99 simulations in a Monte Carlo test procedure, were much higher at greater distances than the expected values under CSR (Fig. 5C). This result demonstrated that the number of fields infested with $G$. pallida found within a given distance (distance matrix) of each individual field was greater than that for a random distribution. The observed $\mathrm{K}$-function values appeared to merge with the expected values at a distance range from 0 to $500 \mathrm{~m}$ and pointing to a random distribution of infested fields. However, at distances of greater than $500 \mathrm{~m}$, the overall observed values were higher than the expected ones and above the confidence interval (envelope), therefore pointing toward aggregation. The maximum absolute deviation test confirmed the visual interpretation of the $\mathrm{K}$-function plot of significant departure from CSR toward spatial clustering $(P=0.01)$ of fields infested with G. pallida.

The nearest neighbor interpolation model illustrated the number of $G$. pallida cysts per hectare and the values of viable eggs intercalated for each of the 18 Voronoi polygons, representing each of the 18 fields infested with G. pallida. Five major polygons in the subset 50 to 250 cysts/ha occupied over $60 \%$ of the interpolated areas, followed by other five polygons estimated under 50 cysts/ha (Fig. 6A). Only one small-sized polygon was estimated over 15,000 cysts/ha. The values of egg viability in the subsets 0.25 to 0.35 and over 0.35 occupied over $65 \%$ of the interpolated areas (Fig. 6B).

The IDW model consisted of 10,000 grids upon which the number of cysts and the values of egg viability were extrapolated using an alpha of 3 , as the inverse square relationship. The subset 1,000 to 8,000 cysts/ha occupied over $85 \%$ of the interpolated areas and only a small area is estimated over 15,000 cysts/ha (Fig. 7A). The values of egg viability in the subset 0.15 to 0.25 occupied over $60 \%$ of the interpolated areas (Fig. 7B). 3-D representations of IDW for the number of cysts and the values of egg viability illustrated important variabilities in their distributions across the interpolated areas (Fig. 7C and D).

The ordinary lognormal kriging model showed high cyst values around a centered focal area in the kriging prediction map (Fig. 8). The kriging standard error map illustrated the degree of confidence associated with the kriging prediction map and showed that the error measurement is lower toward the centered focal area (Fig. 8). The Ste (Matern, M. Stein's parameterization) model was used to fit the experimental variogram with the following initial parameters: sill (2.3), range $(3,427)$, nugget $(1.3)$, and kappa

TABLE 3. Results of the Mantel correlation test for the values of Globodera pallida cyst and egg viability with simulated $P$ value and variance using 1,000 replicates run on a Monte-Carlo simulation

\begin{tabular}{lcc}
\hline Parameters & $\begin{array}{c}\text { Distance matrix versus } \\
\text { number of cysts }\end{array}$ & $\begin{array}{c}\text { Distance matrix versus egg } \\
\text { viability }\end{array}$ \\
\hline Mantel & -0.15 & 0.08 \\
correlation $^{\mathrm{a}}$ & 0.93 & 0.28 \\
Simulated $P^{\text {value }}$ & & \\
Variance $^{\mathrm{b}}$ & 0.01 & 0.02 \\
\hline
\end{tabular}

a Mantel correlation statistic is equivalent to r-squared ( -1 perfect negative correlation, 0 absence of correlation, 1 perfect positive correlation).

b Simulated $P$ values are not significant $(P>0.05)$. 
(0.05). The Ste model adapted to the experimental variogram of cyst values illustrated a weak spatial correlation, as represented by a continuous flat line.

The ordinary kriging prediction model for values of egg viability showed most areas were estimated between 0.25 to 0.35 and the error measurement associated with the prediction map followed similar patterns than the cyst values model (Fig. 9). The Ste model was used to fit the experimental variogram for values of egg viability with the following initial parameters: sill (0.02), range
$(2,831)$, nugget (0.01), and kappa (10) (Fig. 9). The Ste model for values of egg viability showed a relatively strong spatial correlation, as illustrated by a curved line that marked the boundary between correlated and noncorrelated values.

\section{DISCUSSION}

This study provides a holistic analysis of the extent and distribution of fields infested with G. pallida in southern Idaho
A

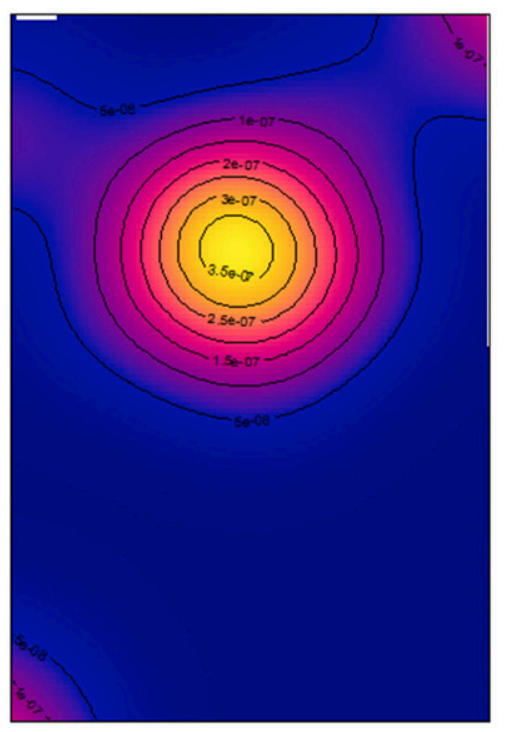

B

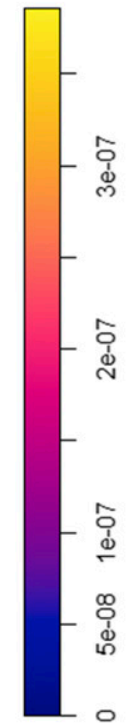

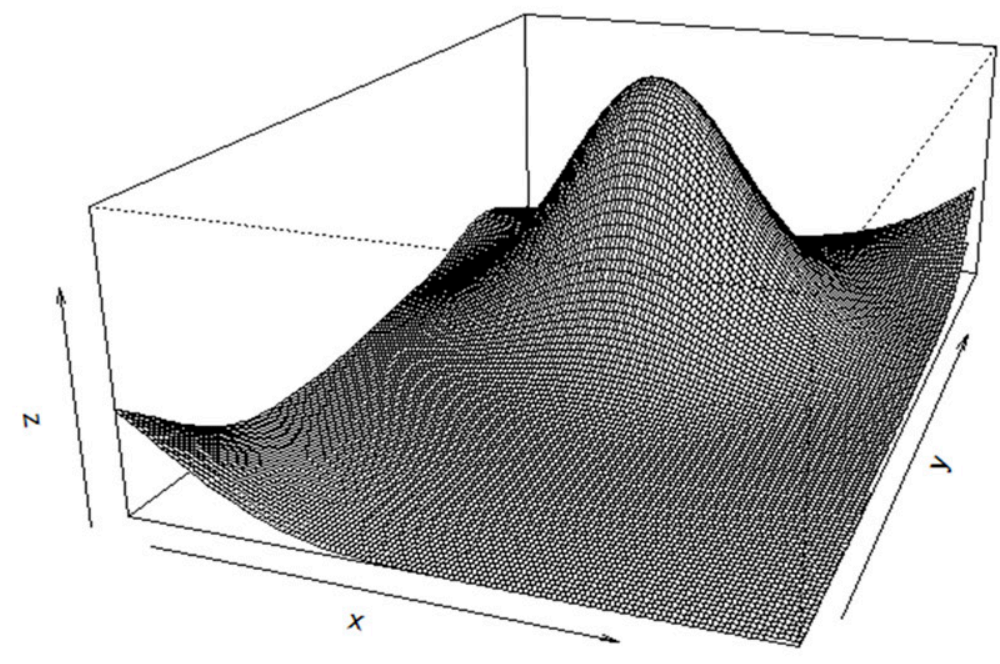

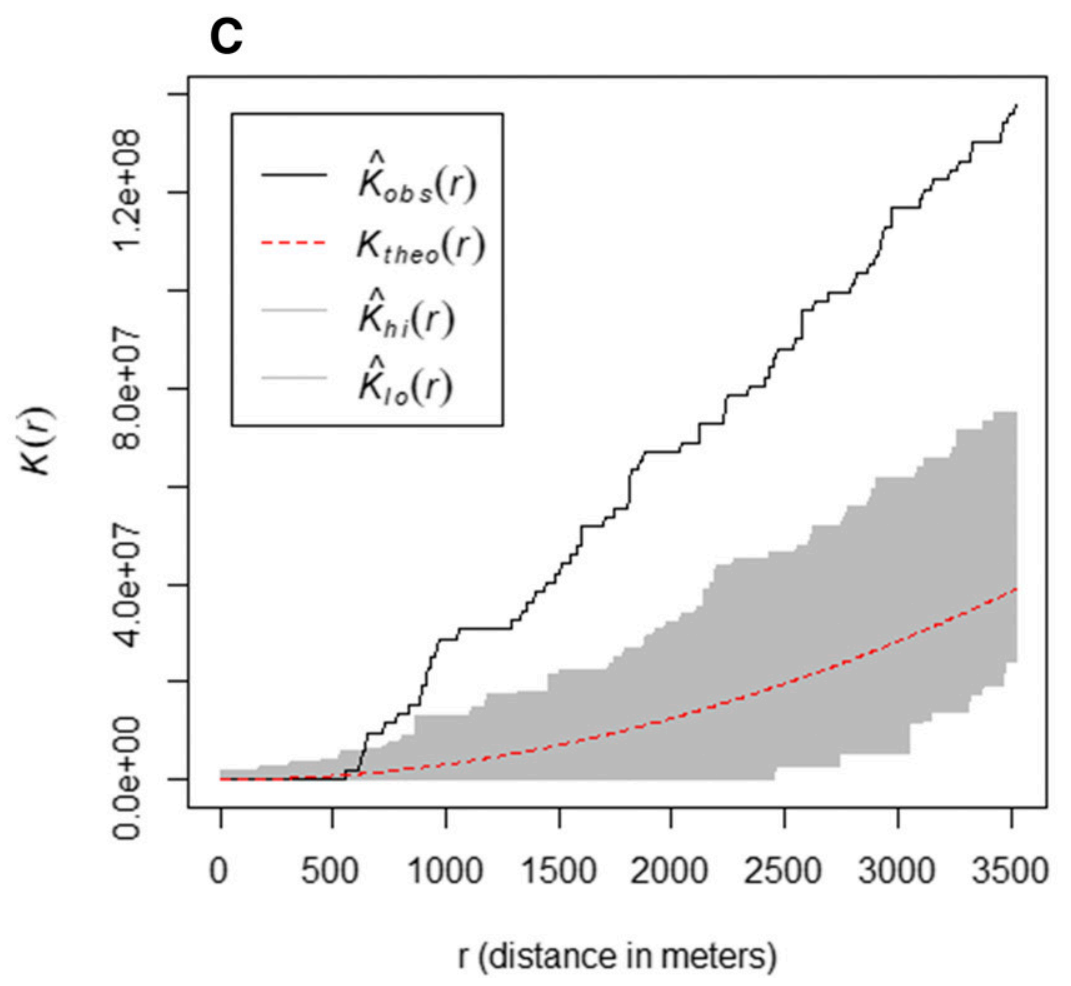

Fig. 5. A, The kernel density estimation (KDE) shows the location of the highest densities of fields infested with Globodera pallida. The color intensity is described as follows: light gray or yellow color or highest number corresponded to highest density and dark gray or blue color or lowest number corresponded to lowest density. A bandwidth of 2,000 $\mathrm{m}$ was used to cover the study area. B, A three-dimensional representation of the KDE analysis showing a smooth peak representing the highest densities of G. pallida-infested fields in the landscape. C, Ripley's K-function plot showing evidence of spatial clustering of fields infested with G. pallida, confirmed by the maximum absolute deviation test of complete spatial randomness $(P=0.01)$ and by the quadrat test $(P=0.003)$. The observed K-function values (black line on plot) are much higher than the expected values under complete spatial randomness (light gray or red dashed line). The gray area represents the envelope or confidence interval of the expected values. 
using spatial analysis techniques. The agglomerative hierarchical cluster analysis classified the distance matrix of fields into three clusters based on the distance separation between all possible pairwise fields. From this analysis, we determined that about $80 \%$ of the fields are in a radius of less than $10 \mathrm{~km}$. Cluster analysis of standardized values of cysts and egg viability indicated three major groups of clusters based on their dissimilarities. Ferris et al. (1971) used cluster analysis to classify population structure of plantparasitic nematodes and found that different community structures differed from soil types. Several cluster algorithms have been used to study the similarity in range and distribution of marine nematode species (Field et al. 1982; Hodda 1986).

The kernel density estimation determined the location of the highest concentration of fields infested with G. pallida. The focal point of locations coincided with the first reports of G. pallida detections during 2006. Based in our analysis, we determined that the spread of G. pallida grew in diameter from the original center of infestation toward the southwest as an ellipsoidal-shaped cluster. Spatial statistical tests confirmed the presence of spatial clustering of fields infested with G. pallida, as illustrated in the Ripley's Kfunction analysis. This result demonstrated that the number of infested fields found within a given distance of each individual field was greater than that for a random distribution. From this clustering arrangement, we determined that $G$. pallida spread followed a contagion effect scenario prior to containment measures, where nearby infested fields contributed to the infestation of new fields, probably through plant materials or agricultural equipment contaminated with infested soil. Similarly, Banks et al. (2012) concluded that the original site of G. pallida and G. rostochiensis introductions may act as a point source for subsequent spread occurring at a relatively constant rate over time. Similar aggregated patterns of potato cyst nematodes and other plant-parasitic nematodes have been reported for individual fields (Avendaño et al. 2003; Noe and Campbell 1985; Schomaker and Been 1999; Shaukat and Khan 1993). It is unlikely that the recent G. pallida presence in southern Idaho is associated with new G. pallida entry from outside Idaho. Our assessment is based on previous studies indicating that $G$. pallida populations differ between themselves generally only in areas throughout Europe and South America where G. pallida has been long-established (based on molecular phylogenetic analysis), suggesting multiple waves of G. pallida entry (Grenier et al. 2010; Picard et al. 2004, 2007; Plantard et al. 2008).

Using deterministic spatial interpolation techniques, we enumerated the number of $G$. pallida cysts and the values of egg viability in associated areas close to initial infestation foci. The models used for spatial interpolation predicted the contagion effect of G. pallida to nearby fields. The IDW model differed from the nearest neighbor approach due to the nature of the model calculation. In the case of IDW, a weighted measurement of multiple number of cysts is taken from different nearby fields instead of relying on a single field measurement for prediction, as is done with nearest neighbor modeling. As the distribution of the number of cysts varied greatly between fields, we determined for this study that IDW was the best model to describe the contagion effect. For egg viability, we determined that nearest neighbor and IDW models yielded relatively similar prediction maps in the subset ranging from under 0.05 to 0.15 ; however, they failed to provide similar results as the values of egg viability increase. Therefore, we determined that IDW was the best deterministic model adapted for the interpolation of the values of egg viability. The variability in the number of cysts per hectare observed in this study could be explained by the relative success of quarantine measures imposed on infested fields, where potato plantings are prohibited, and entrance is limited to authorized personnel only, leading to a disruption of the initial G. pallida spread momentum.

The use of ordinary kriging for building a stochastic interpolation model unveiled some inherent limitations when applied to a restrained and skewed dataset. A kriging interpolation model is built on an experimental variogram to make predictions from known to unknown locations using estimated variations in the known data values. Mantel correlation test previously indicated no
A

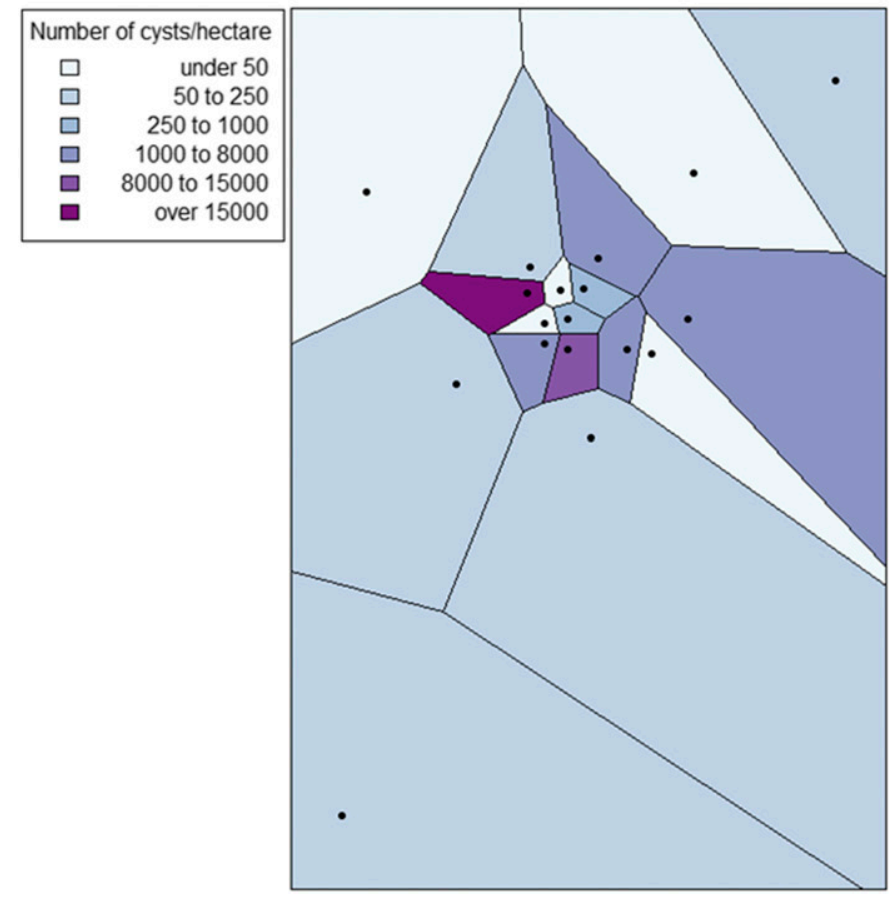

B

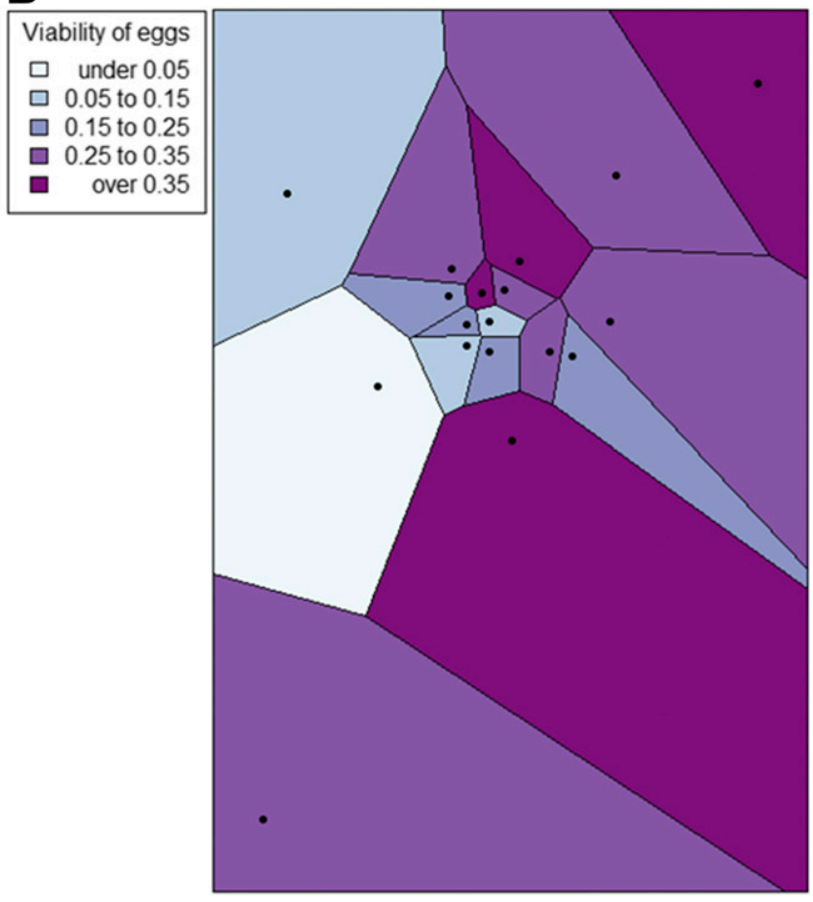

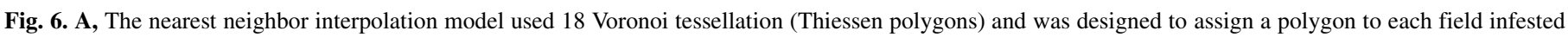

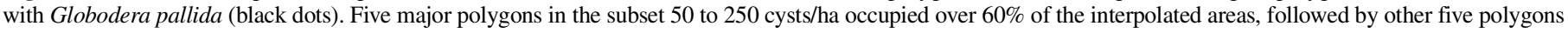
estimated under 50 cysts/ha. B, The values of $G$. pallida egg viability in the subsets 0.25 to 0.35 and over 0.35 occupied over $65 \%$ of the interpolated areas. 
significant relationship between field distance matrix and the cyst numbers collected. The experimental variogram built for the variable cyst numbers showed weak spatial correlation indicating the absence of spatial dependency. As a result, kriging prediction map was associated with large error measurement values indicating high level of uncertainties in interpolated areas for cyst numbers. Because of the absence of spatial correlation, the use of IDW as a deterministic interpolation model for cyst numbers is recommended.

The experimental variogram adapted for the values of egg viability showed a relatively strong spatial correlation indicating the presence of spatial dependency. The relative normal distribution of the egg viability dataset explained this result, and the Ste ordinary kriging interpolation model seemed to reduce the level of uncertainty associated with the kriging prediction map. Although the Mantel correlation test for egg viability showed no significant spatial correlation, the Ste ordinary kriging was found to be a better model for spatial correlation using advanced spatial analysis techniques. We determined that both IDW and ordinary kriging provided comparatively similar prediction maps for the interpolation of the values of egg viability.

Various interpolation models have been applied for studying the spatial distribution of plant-parasitic nematodes in individual fields with gridded sampling methods (microscale) (Caswell and Chellemi 1986; Evans et al. 2003; Farias et al. 2002; Webster and Boag 1992). However, to our knowledge, this study represents the first use of stochastic interpolation models for plant-parasitic nematodes at a regional level (macroscale). We determined that
A

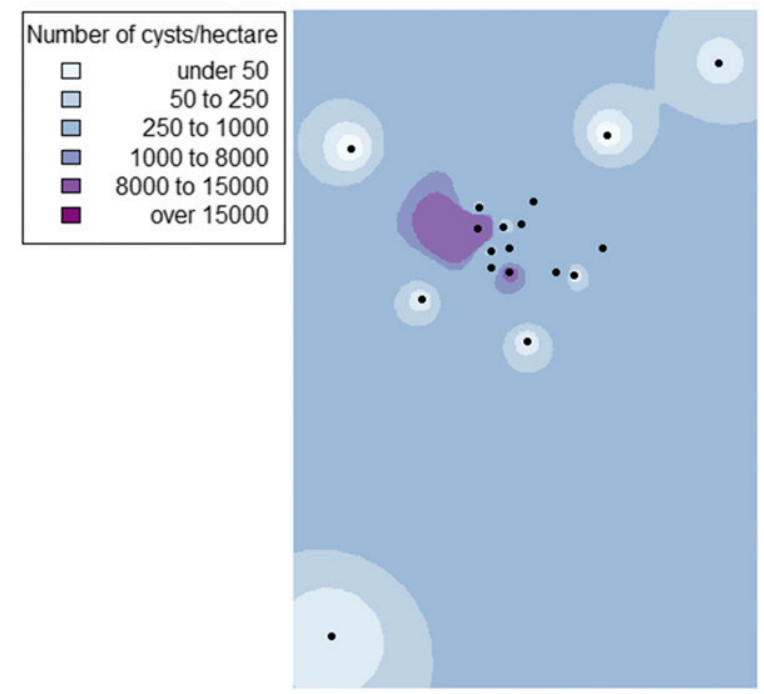

C

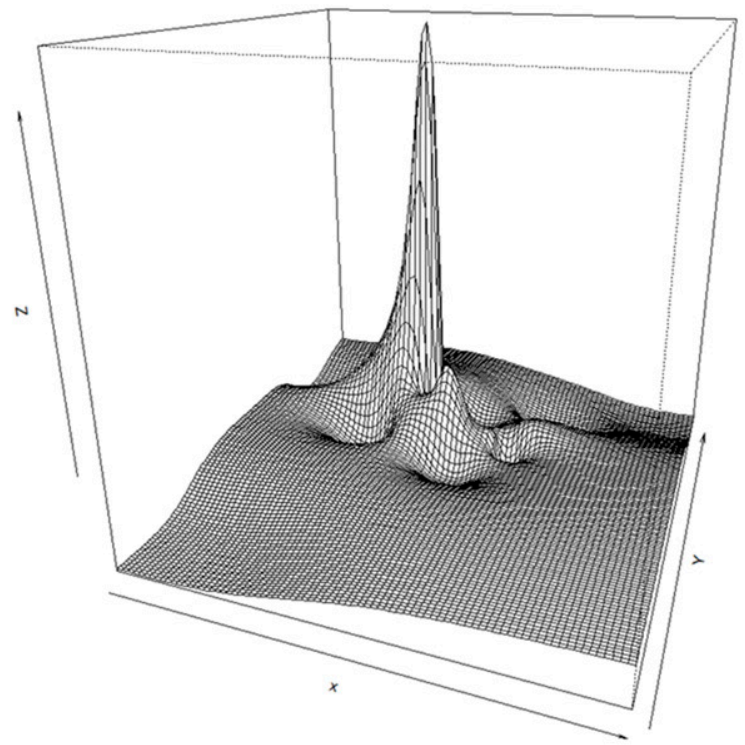

B

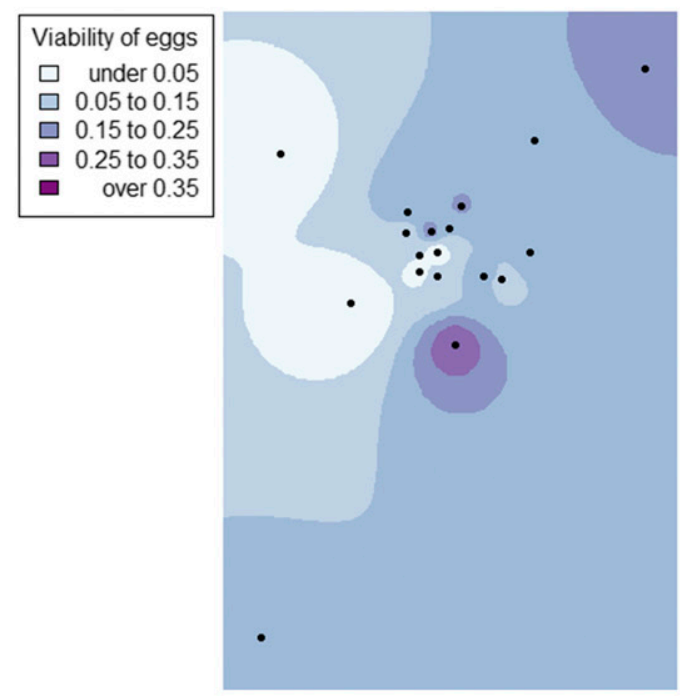

D

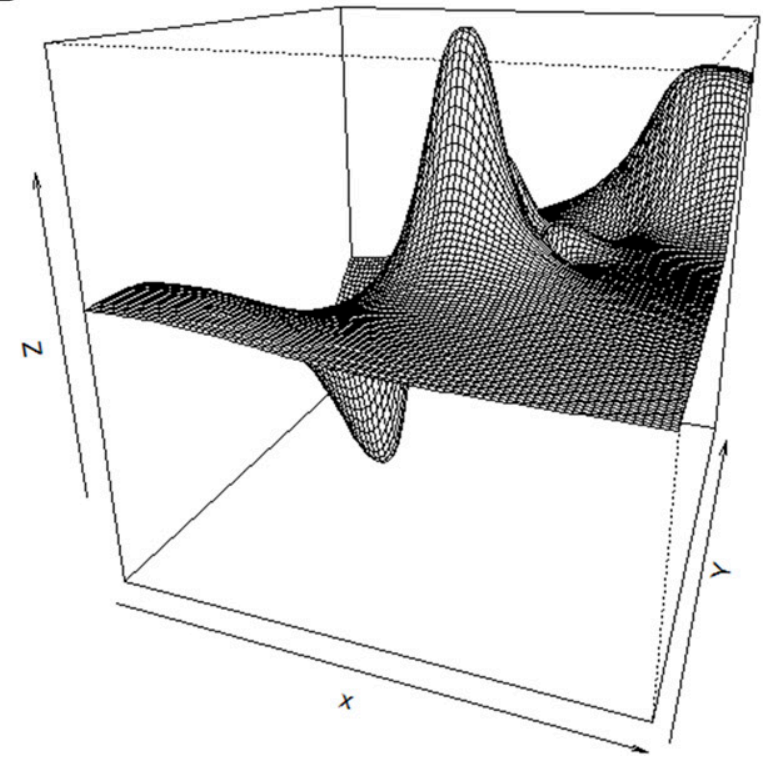

Fig. 7. A, The inverse distance weighting (IDW) surface consisted of 10,000 grids upon which the number of Globodera pallida cysts and the values of egg viability (black dots) were extrapolated using an alpha of 3, as the inverse square relationship. The subset 1,000 to 8,000 cysts/ha occupied over $85 \%$ of the interpolated areas and only a small area is estimated over 15,000 cysts/ha. B, The values of G. pallida egg viability in the subset 0.15 to 0.25 occupied over $60 \%$ of the interpolated areas. C, Three-dimensional representations of the IDW for the number of G. pallida cysts. The model showed a relatively smooth surface with high and low peaks in the interpolated locations corresponding to areas of high number of G. pallida cysts per hectare. D, Three-dimensional representations of the IDW for the values of G. pallida egg viability. The model showed many smooth peaks in the interpolated locations corresponding to areas of low and high values of G. pallida egg viability. 
stochastic interpolation models for plant-parasitic nematodes applied to a macroscale level are subjected to strong variations when the datasets are restrained and skewed, as was the case in this study.

Based on the spatial aggregation of fields infested with G. pallida, with an average of 4,263 cysts/ha and egg viability of 0.25 , we determined that active programs of quarantine and eradication can limit the spread of G. pallida in southern Idaho. An eradication program requires strict containment protocols and the prohibition of growing potato in infested sites. Intensive soil sampling and testing are required as part of the program to monitor and evaluate the progress of G. pallida eradication at regular time intervals. The use of G. pallida resistant potato varieties, trap crops, crop rotations, biofumigants and biocontrol agents is a crucial first step to rapidly reduce G. pallida population densities to undetected levels and to return previously infested fields to potato production. Studies found that the use of Solanum sisymbriifolium (trap crop), Trichoderma harzianum, and Plectosphaerella cucumerina (fungal biocontrol agents) showed significant reduction of $G$. pallida reproduction rate in greenhouse experiments (Contina et al. 2017; Dandurand and Knudsen 2016).

Globodera rostochiensis was found in the Sharon region of Israel in 1954 and in 1965 where potatoes are grown in the winter. After

\section{Kriging prediction}

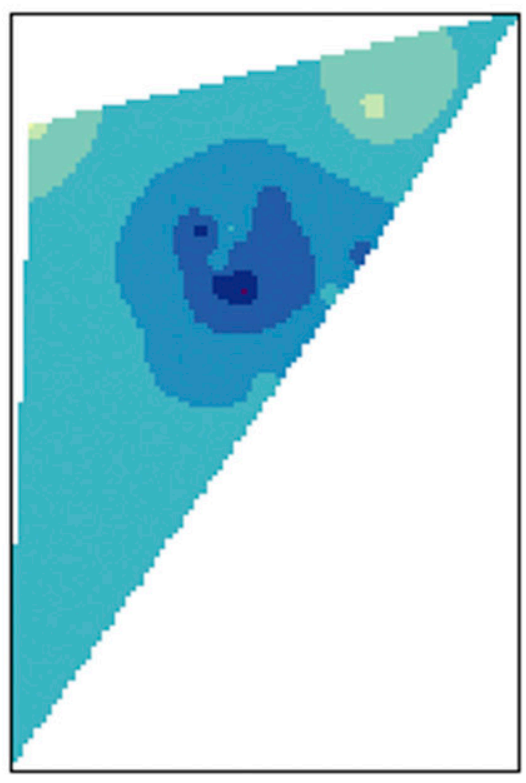

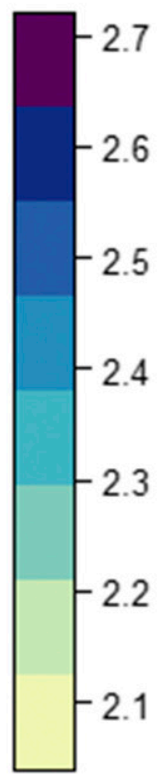

Kriging standard error

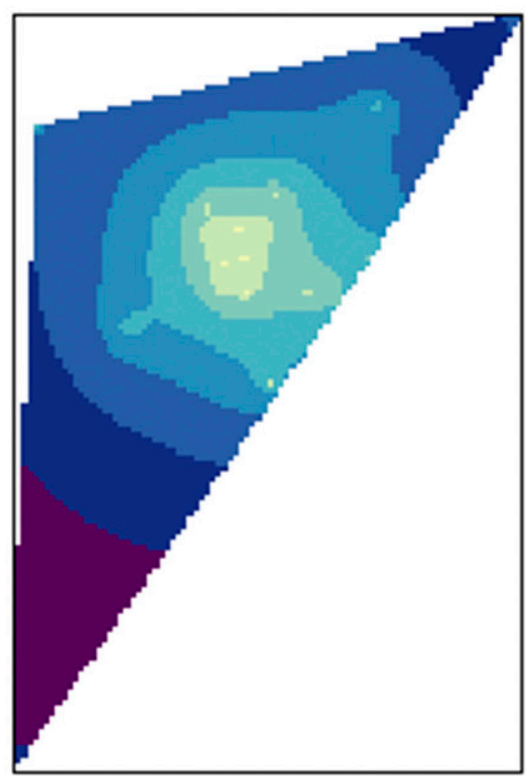

1.58

1.56

1.54

$-1.52$

$-1.50$

\section{Experimental variogram and fitted variogram model}

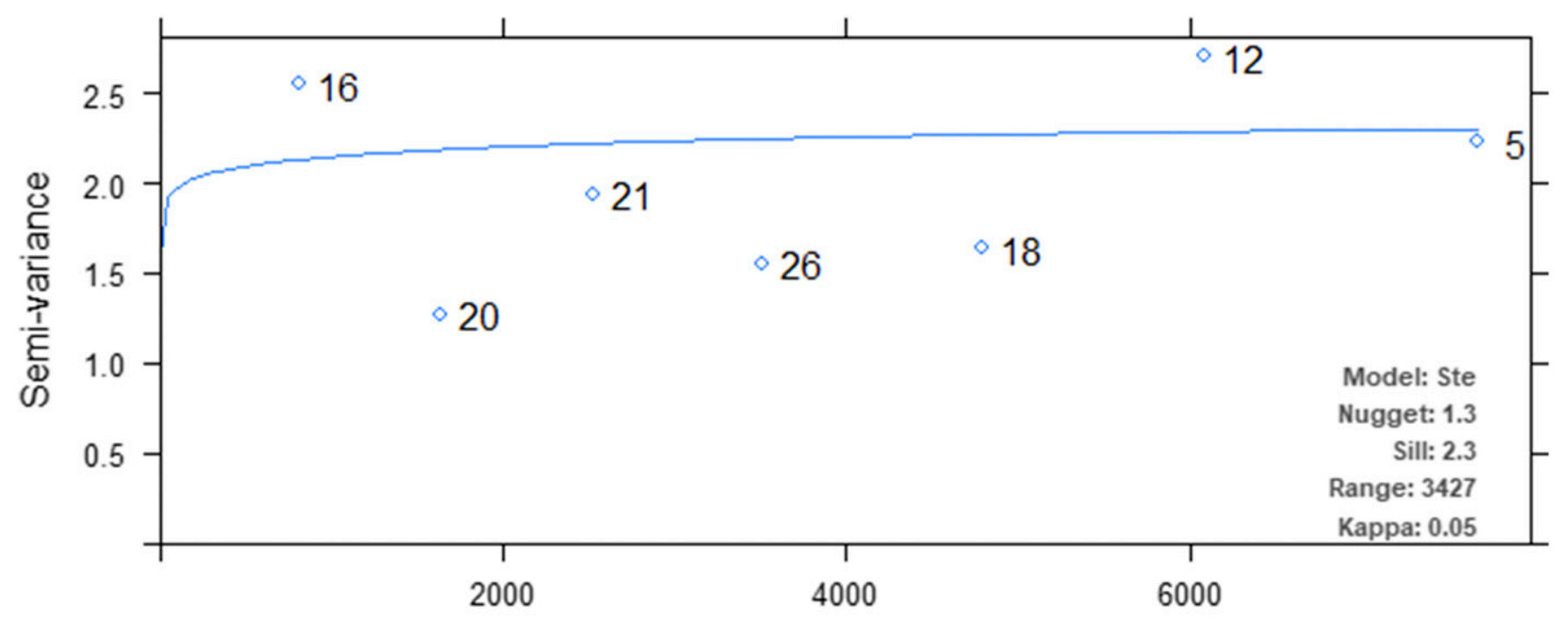

\section{Distance}

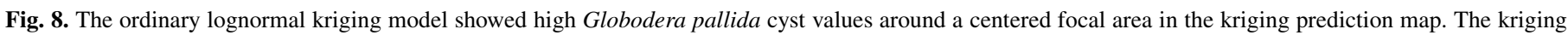

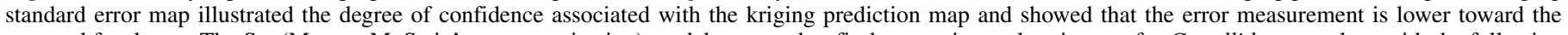

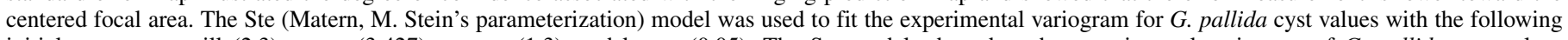

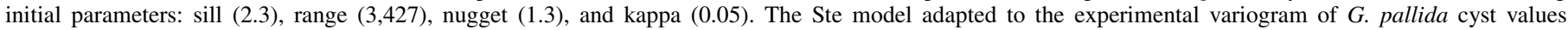
illustrated a weak spatial correlation, as represented by a continuous flat line. 
detection, eradication was carried out by soil fumigation with ethylene dibromide and soil testing was performed at regular intervals. In 1987, the European and Mediterranean Plant Protection Organization (EPPO) reported that Israel was declared free from this pest, after a negative $G$. rostochiensis presence in subsequent soil testing (Anonymous 1987). G. rostochiensis eradication from Western Australia (first found in 1986) has proven to be another successful program. G. rostochiensis has not been detected since 1989 in Western Australia where the intensity of soil sampling used provides 96 to $100 \%$ G. rostochiensis detection probability (Anonymous 2010). In 2010, after 24 years of G. rostochiensis eradication, Western Australia was declared free of this pest.
G. pallida was detected in Finland in four fields in 2002 and two fields in 2004. After 9 years of eradication program, all soil samples tested in 2011 gave negative results for the presence of G. pallida (Anonymous 2012).

This study provides a scientifically based decision method that promotes eradication measures instead of management for G. pallida in Idaho. To our knowledge, this is the first use of spatial analysis for understanding G. pallida distribution at a macroscale level in Idaho. The use of spatial analysis in risk assessment models provides important information on the distribution, potential spread, and control strategies for exotic plant-parasitic nematodes. The tools and methods provided in

\section{Kriging prediction}

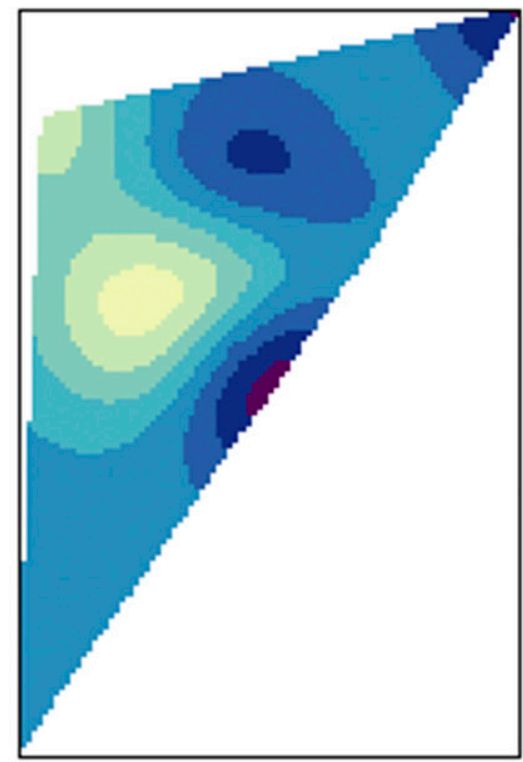

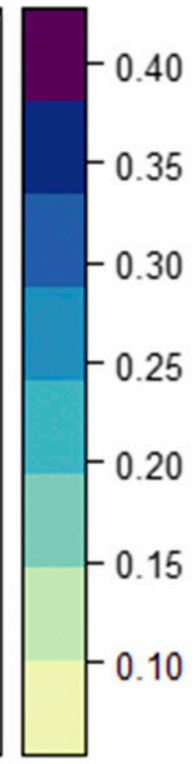

Kriging standard error

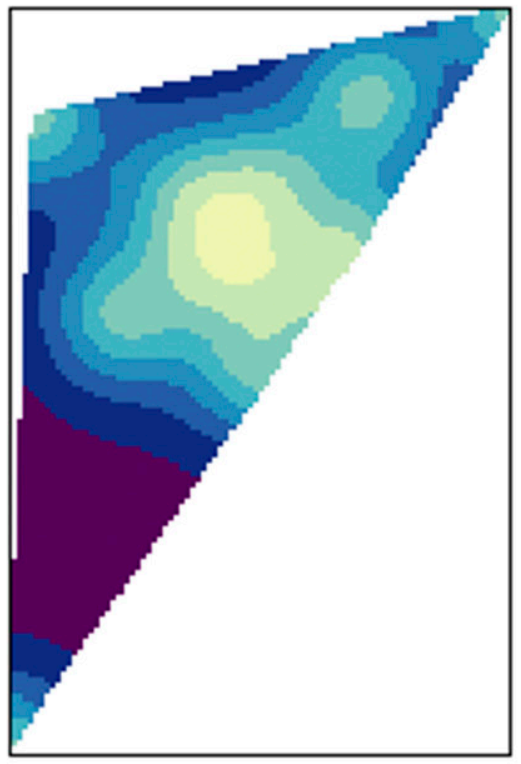

\section{Experimental variogram and fitted variogram model}

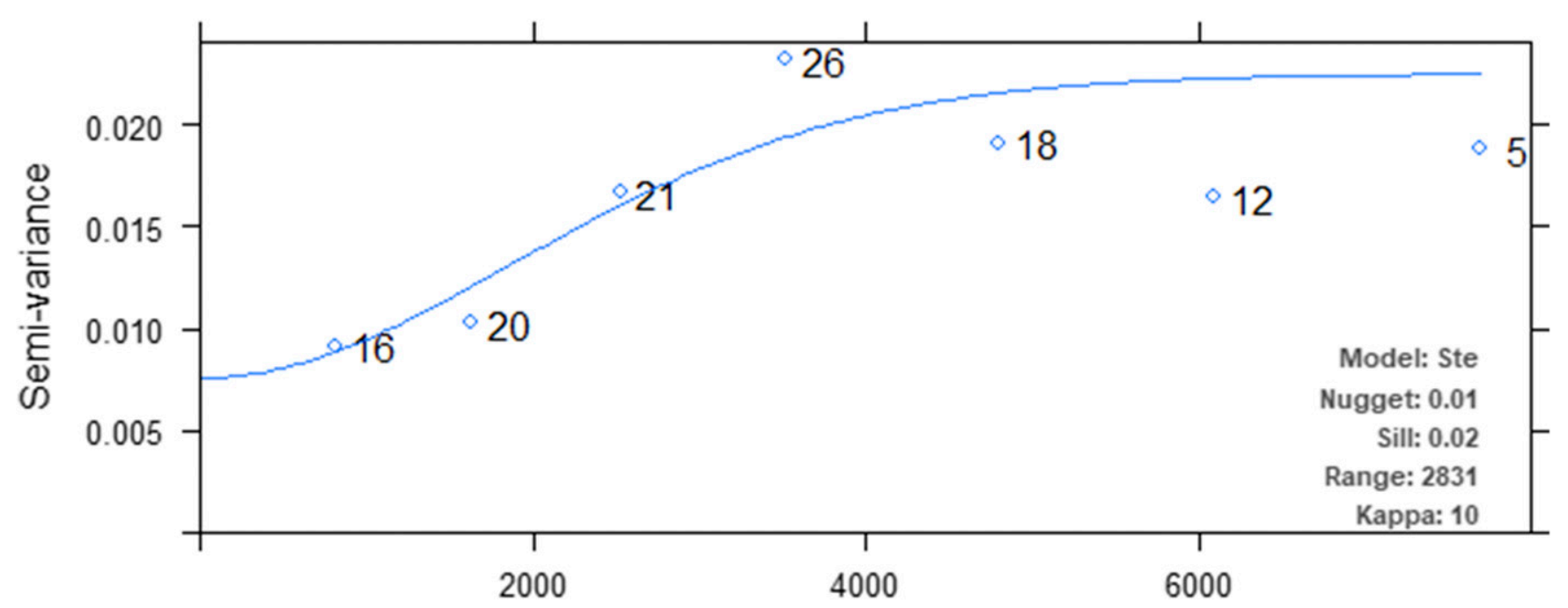

\section{Distance}

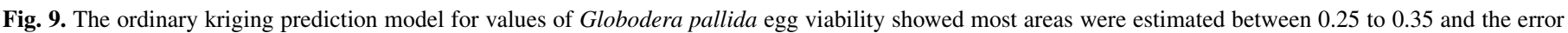

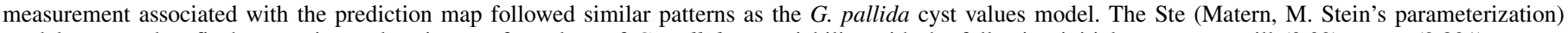

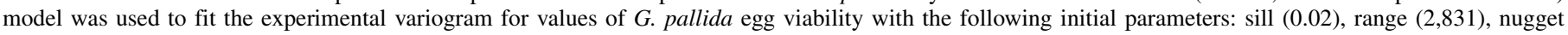

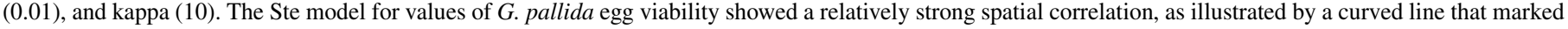
the boundary between correlated and noncorrelated values. 
this study should facilitate comprehensive approaches to improve G. pallida control and eradication programs as well as to raise public awareness of the problems surrounding this economically important potato pest.

\section{ACKNOWLEDGMENTS}

This project is part of a Ph.D. dissertation of the first author. We thank T. Gresham of the USDA Animal and Plant Health Inspection Service for providing the field data for analysis; S. Radil for providing technical guidance for the basic descriptive and inferential spatial analysis in R used in this study, and the Senior Editor and the anonymous reviewers for their constructive comments.

\section{LITERATURE CITED}

Anonymous. 1987. Non-occurrence of Globodera rostochiensis in Israel. Online publication. European and Mediterranean Plant Protection Organization (EPPO) Reporting Service No. 18. https://gd.eppo.int/reporting/ article-5754

Anonymous. 2010. Eradication of potato cyst nematode (PCN) from Western Australia. Online publication. International Plant Protection Convention (IPPC). https://www.ippc.int/en/countries/australia/pestreports/2010/09/ eradication-of-potato-cyst-nematode-pen-from-western-australia/

Anonymous. 2012. Situation of Globodera pallida in Finland in 2011. Online publication. European and Mediterranean Plant Protection Organization (EPPO) Reporting Service No. 04. https://gd.eppo.int/reporting/article-1900.

Anonymous. 2014. Potatoes 2013 Summary. Online publication. USDANASS. https://www.census.gov/history/pdf/idahopotatoes2014.pdf

Anonymous. 2017a. Potato stocks. Online publication. USDA. http://usda. mannlib.cornell.edu/usda/nass/PotaStoc//2010s/2017/PotaStoc-06-16-2017. pdf

Anonymous. 2017b. Pale cyst nematode (PCN) eradication program, Idaho Falls, Idaho. Second Quarter Report (April-June). Online publication. USDA-APHIS. https://www.aphis.usda.gov/plant_health/plant_pest_info/ potato/downloads/pcndocs/surveyupdates/2017/pcn-2nd-quarter-2017.pdf

Armstrong, M., and Boufassa, A. 1988. Comparing the robustness of ordinary kriging and lognormal kriging: Outlier resistance. Math. Geol. 20:447-457.

Avendaño, F., Schabenberger, O., Pierce, F. J., and Melakeberhan, H. 2003. Geostatistical analysis of field spatial distribution patterns of soybean cyst nematode. Agron. J. 95:936-948.

Baldwin, J. G., and Mundo-Ocampo, M. 1991. Heteroderinae cyst and noncyst forming nematodes. Pages 275-362 in: Manual of Agricultural Nematology. W. R. Nickle, ed. Decker Inc., New York.

Banks, N. C., Hodda, M., Singh, S. K., and Matveeva, E. M. 2012. Dispersal of potato cyst nematodes measured using historical and spatial statistical analyses. Phytopathology 102:620-626.

Behrens, E. 1975:Pages 12-26 in: Globodera Skarbilovic, 1959, eine selbstaendige Gattung in der Unterfamilie Heteroderinae Skarbilovic, 1947 (Nematoda: Heteroderidae). Vortragstagung zu aktuellen Problemen der Phytonematologie am 29/5/1975 in Rostock. Manuskriptdruck der Vortraege, Rostock.

Caswell, E. P., and Chellemi, D. A. 1986. A geostatistical analysis of spatial pattern of Rotylenchulus reniformis in Hawaiian pineapple field. J. Nematol. 18:603.

Contina, J. B., Dandurand, L. M., and Knudsen, G. R. 2017. Use of GFPtagged Trichoderma harzianum as a tool to study the biological control of the potato cyst nematode Globodera pallida. Appl. Soil Ecol. 115:31-37.

Cressie, N. 1993. Geostatistics: A tool for environmental modelers. Pages 415-421 in: Environmental Modelling with GIS. M. F. Goodchild, B. O. Parks, and L. T. Steyaert, eds. Oxford University Press Inc., New York.

Dandurand, L. M., and Knudsen, G. R. 2016. Effect of the trap crop Solanum sisymbriifolium and two biocontrol fungi on reproduction of the potato cyst nematode Globodera pallida. Ann. Appl. Biol. 169:180-189.

Dinardo-Miranda, L. L., and Fracasso, J. V. 2009. Spatial distribution of plantparasitic nematodes in sugarcane fields. Sci. Agric. 66:188-194.

Englund, E. J. 1993. Spatial simulation: Environmental applications. Pages 432-437 in: Environmental Modelling with GIS. M. F. Goodchild, B. O. Parks, and L. T. Steyaert, eds. Oxford University Press Inc., New York.

Evans, K., Franco, J., and Scurrah, M. M. 1975. Distribution of species of potato cyst-nematodes in South America. Nematologica 21:365-369.

Evans, K., and Stone, A. R. 1977. A review of the distribution and biology of the potato cyst nematodes Globodera rostochiensis and G. pallida. Int. J. Pest Manage. 23:178-189.

Evans, K., Webster, R., Barker, A., Halford, P., and Russel, M. 2003. Mapping infestations of potato cyst nematodes and the potential for spatially varying application of nematicides. Precis. Agric. 4:149-162.
Farias, P. R. S., Sánchez-Vila, X., Barbosa, J. C., Vieira, S. R., Ferraz, L. C. C. B., and Solís-Delfin, J. 2002. Using geostatistical analysis to evaluate the presence of Rotylenchulus reniformis in cotton crops in Brazil: Economic implications. J. Nematol. 34:232-238.

Fenwick, D. W. 1940. Methods for the recovery and counting of cysts of Heterodera schachtii from soil. J. Helminthol. 18:155-172.

Ferris, H., Jetter, K. M., Zasada, I., Chitambar, J. J., Venette, R. C., Klonsky, K. M., and Becker, J. O. 2003. Risk assessment of plant-parasitic nematodes. Pages 99-119 in: Exotic Pests and Diseases: Biology and Economics for Biosecurity. D. A. Summer, ed. Iowa State University Press.

Ferris, V. R., Ferris, J. M., Bernard, R. L., and Probst, A. H. 1971. Community structure of plant-parasitic nematodes related to soil types in Illinois and Indiana soybean fields. J. Nematol. 3:399-408.

Field, J. G., Clarke, K. R., and Warwick, R. M. 1982. A practical strategy for analyzing multispecies distribution patterns. Mar. Ecol. Prog. Ser. 8:37-52.

Francl, L. J. 1986. Spatial analysis of Heterodera glycines populations in field plots. J. Nematol. 18:183-189.

Gavassoni, W. L., Tylka, G. L., and Munkvold, G. P. 2001. Relationships between tillage and spatial patterns of Heterodera glycines. Phytopathology 91:534-545.

Grenier, E., Fournet, S., Petit, E., and Anthoine, G. 2010. A cyst nematode 'species factory' called the Andes. Nematology 12:163-169.

Hafez, S. L., Sundararaj, P., Handoo, Z. A., Skantar, L., Carta, K., and Chitwood, D. J. 2007. First report of the pale cyst nematode, Globodera pallida, in the United States. Plant Dis. 91:325.

Haining, R. 2003. Spatial Data Analysis: Theory and Practice. Cambridge University Press, Cambridge, UK.

Hodda, M. 1986. Cluster analysis of marine nematodes. Nematologica 32: 419-437.

Hodda, M., and Cook, D. C. 2009. Economic impact from unrestricted spread of potato cyst nematodes in Australia. Phytopathology 99:1387-1393.

Jatala, P. 1994. Biology and management of nematode parasites of potato in developing countries. Page 215 in: Advances in Potato Pest Biology and Management. M. L. Powelson, G. W. Zehnder, and R. K. Jansson, eds. American Phytopathological Society, St. Paul, MN.

Jenkins, W., Mather, B., and Munson, D. 1985. Nearest neighbor and generalized inverse distance interpolation for Fourier domain image reconstruction. Proc. IEEE 73:1069-1072.

Jones, F. G. W. 1970. The control of the potato cyst nematode. J. R. Soc. Arts 118:179-199.

Jones, F. G. W., and Parrott, D. M. 1968. Potato production using resistant varieties on land infested with potato cyst-eelworm, Heterodera rostochiensis Woll. Outlook Agric. 5:215-222.

Kaufman, L., and Rousseeuw, P. J. 1990. Finding Groups in Data: An Introduction to Cluster Analysis. Wiley, New York.

Kenkel, N. C. 1993. Modeling Markovian dependence in populations of Aralia nudicaulis. Ecology 74:1700-1706.

Legendre, P., Fortin, M. J., and Borcard, D. 2015. Should the Mantel test be used in spatial analysis? Methods Ecol. Evol. 6:1239-1247.

Madden, L. V., and Hughes, G. 1995. Plant disease incidence: Distributions, heterogeneity, and temporal analysis. Annu. Rev. Phytopathol. 33:529-564.

Mantel, N. 1967. The detection of disease clustering and a generalized regression approach. Cancer Res. 27:209-220.

Mantel, N., and Valand, R. S. 1970. A technique of non-parametric multivariate analysis. Biometrics 26:547-558.

Massee, G. 1913. Nematodes or eelworms. Kew Bull. 9:343-351.

Minnis, S. T., Haydock, P. P. J., Ibrahim, S. K., Grove, I. G., Evans, K., and Russell, M. D. 2000. The occurrence and distribution of potato cyst nematodes in England and Wales. Asp. Appl. Biol. 59:1-9.

Minnis, S. T., Haydock, P. P. J., Ibrahim, S. K., Grove, I. G., Evans, K., and Russell, M. D. 2002. Potato cyst nematodes in England and Wales: Occurrence and distribution. Ann. Appl. Biol. 140:187-195.

Noe, J. P., and Campbell, C. L. 1985. Spatial pattern analysis of plant-parasitic nematodes. J. Nematol. 17:86-93.

Ogiga, I. R., and Estey, R. H. 1974. The use of Meldola Blue and Nile Blue A for distinguishing dead from living nematodes. Nematologica 20:271-276.

Oliver, M. A. 1990. Kriging: A method of interpolation for Geographical Information Systems. Int. J. Geogr. Inf. Sci. 4:313-332.

Picard, D., Plantard, O., Scurrah, M., and Mugniéry, D. 2004. Inbreeding and population structure of the potato cyst nematode (Globodera pallida) in its native area (Peru). Mol. Ecol. 13:2899-2908.

Picard, D., Sempere, T., and Plantard, O. 2007. A northward colonization of the Andes by the potato cyst nematode during geological times suggests multiple host-shifts from wild to cultivated potatoes. Mol. Phylogenet. Evol. 42:308-316.

Plantard, O., Picard, D., Valette, S., Scurrah, M., Grenier, E., and Mugniéry, D. 2008. Origin and genetic diversity of Western European populations of the potato cyst nematode (Globodera pallida) inferred from mitochondrial sequences and microsatellite loci. Mol. Ecol. 17:2208-2218. 
Porazinska, D. L., Giblin-Davis, R. M., Powers, T. O., and Thomas, W. K. 2012. Nematode spatial and ecological patterns from tropical and temperate rainforests. PLoS One 7:e44641.

Prentice, I. C., and Werger, M. J. A. 1985. Clump spacing in a desert dwarf shrub community. Vegetatio 63:133-139.

Pylypenko, L. A. 1999. The interrelations in a system parasite-host plant at the globoderosis. Ph.D. thesis. National Agrarian University, Kyiv, Ukraine.

R Core Team. 2017. R: A Language and Environment for Statistical Computing. R Foundation for statistical computing, Vienna, Austria. http://www. R-project.org/

Ripley, B. D. 1976. The second-order analysis of stationary point processes. J. Appl. Probab. 13:255-266.

Ripley, B. D. 1977. Modelling spatial patterns. J. R. Stat. Soc. B 38:172-212.

Ripley, B. D. 1981. Spatial Statistics. Wiley, New York.

Rousseeuw, P. J. 1986. A visual display for hierarchical classification. Pages 743-748 in: Data Analysis and Informatics IV. E. Diday, Y. Escoufier, L. Lebart, J. Pagés, Y. Schektman, and R. Tomassone, eds. Elsevier Science Pub. Co., New York.

Royle, A. G., Clausen, F. L., and Frederiksen, P. 1981. Practical universal Kriging and automatic contouring. Geoprocessing 1:377-394.

Schomaker, C. H., and Been, T. H. 1999. A model for infestation foci of potato cyst nematodes Globodera rostochiensis and G. pallida. Phytopathology 89: 583-590.

Shaukat, S. S., and Khan, A. 1993. Spatial pattern analysis of three nematode populations associated with chili. Fundam. Appl. Nematol. 16:473-478

Silverman, B. W. 1986. Density Estimation for Statistics and Data Analysis. Chapman and Hall, New York.

Skantar, A. M., Handoo, Z. A., Carta, L. K., and Chitwood, D. J. 2007. Morphological and molecular identification of Globodera pallida associated with potato in Idaho. J. Nematol. 39:133-144.

Skarpe, C. 1991. Spatial patterns and dynamics of woody vegetation in an arid savanna. J. Veg. Sci. 2:565-572.
Stein, M. L. 1999. Interpolation of Spatial Data: Some Theory for Kriging. Springer-Verlag, New York

Sterner, R. W., Ribic, C. A., and Schatz, G. E. 1986. Testing for life historical changes in spatial patterns of four tropical tree species. J. Ecol. 74:621-633.

Stone, A. R. 1972. The round cyst species of Heterodera as a group. Ann. Appl. Biol. 71:280-283.

Strachan, J., and Taylor, T. H. 1926. Potato eelworm. J. Min. Agric. 32: 941-947.

Talavera, M., Andreu, M., Valor, H., and Tobar, A. 1998. Nematodos fitoparásiticos en áreas productoras de patata de Motril y Salobreña. Invest Agric. Prod. Prot. Veg. 13:87-95.

Thomas, R. W. 1977. An introduction to quadrat analysis. CATMOG 12. Geo Abstracts Ltd., Norwich, UK.

Tobler, W. 1979. Cellular geography. Pages 379-386 in: Philosophy in Geography. S. Gale and G. Olsson, eds. Reidel, Dordrecht, Netherlands.

Trudgill, D. L., Elliott, M. J., Evans, K., and Phillips, M. S. 2003. The white potato cyst nematode (Globodera pallida): A critical analysis of the threat in Britain. Ann. Appl. Biol. 143:73-80.

Turner, S. J. 1996. Population decline of potato cyst nematodes (Globodera rostochiensis and G. pallida) in field soils in Northern Ireland. Ann. Appl. Biol. 129:315-322.

Turner, S. J., and Rowe, J. A. 2006. Cyst nematodes. Pages 91-122 in: Plant Nematology. R. N. Perry and M. Moens, eds. CABI, Wallingford, UK.

Vasyutin, A. S., and Yakovleva, V. A. 1998. Globodera in potatoes in Russia. Kartofel'. I Ovoshchi 6:29-32.

Wackernagel, H. 2003. Multivariate geostatistics. Springer-Verlag, Berlin.

Ward, J. H. 1963. Hierarchical grouping to optimize an objective function. J. Am. Stat. Assoc. 22:151-183.

Webster, R., and Boag, B. 1992. Geostatistical analysis of cyst nematodes in soil. J. Soil Sci. 43:583-595. 